\title{
REPRESENTAÇÕES GRÁFICAS ESPACIAIS EM GEOCIÊNCIAS AUXILIADAS POR COMPUTADOR*
}

\author{
JORGE KAZUO YAMAMOTO**
}

\begin{abstract}
This paper presents a revision of the current methodology for computer aided graphical displaying of geological data. The main techniques and mathematical concepts of computer graphics, i.e., interpolation, determination of convex hull, determination of the position of a point relative to convex hull, automatic contouring, and hidden line elimination are presented and discussed. Aplications over real topographical and chemical data from the Anitápolis Alkaline Complex, State of Santa Catarina, are also discussed.
\end{abstract}

INTRODUÇÃo A interpretação de resultados obtidos em pesquisas geológicas é feita geralmente sobre perfis, plantas, mapas e blocos-diagramas. Essas formas de representação gráfica de dados geológicos permitem sempre o estudo das variações e/ou inter-relações espaciais dos parâmetros investigados.

Nessas figuras podem-se representar tanto informaçōes qualitativas como quantitativas. Quando os dados forem de natureza qualitativa, isto é, resultados de observaçöes geologicas, utiliza-se uma simbologia adequada para representá-los. Quando quantitativos, resultados de medidas e/ou análises como dados estruturais, geoquímicos, geofísicos, sedimento16 gicos, entre outros, podem ser representados sob as mais diversas formas gráficas, entre as quais a mais comum é pelas curvas de isovalores em mapas de contorno. Além dos mapas de contorno, os dados numéricos podem ser representados em blocos-diagramas, plantas e perfis. Essas representações gráficas podem ser programadas e obtidas no computador com grandes vantagens, tais como: rapidez, precisão e versatilidade. Entretanto, segundo Pettinati (1983), no Brasil ainda não é usual a utilização de computadores para esse fim pela existência de mão-de-obra razoavelmente capacitada e de custo não muito elevado para processamento manual, pela escassez de equipamentos específicos para a produção de desenhos diretamente pelo computador, bem como pela indisponibilidade de programas e sistemas adequados às necessidades das empresas usuárias. Entre os fatores citados por aquele autor, acredita-se que, atualmente, ao menos em Geologia, somente o último tende a limitar a aplicação da computação gráfica para a produção automática de desenhos.

Os programas de computação hoje disponíveis comercialmente para fins gráficos, além de serem relativamente antigos, com Symap (Dougenick \& Sheeham 1975) e . Sur-

II (Sampson 1975), geralmente não proporcionam resultados satisfatórios a seus usuários pela falta de controle sobre os mesmos. Por exemplo, o programa Surface II, apresenta sérios problemas, entre os quais o principal é a intersecção das curvas de contorno, quando estas são suavizadas. Além disso, sua execução em computadores com memória virtual (atualmente a maioria) é muito demorada em razão da ineficiente estrutura de overlay do programa, justamente planejada para ocupar o menor espaço de memória durante sua execução, pois os computadores disponíveis na época não apresentavam memória suficiente para comportar todo o programa de uma única vez. Por outro lado, além da indisponibilidade de programas para fins gráficos em Geologia, há também a falta de conhecimento, pelo geólogo, das técnicas e dos conceitos matemáticos de computação gráfica necessários ao desenvolvimento de programas de computação segundo suas necessidades específicas.

Este trabalho tem por objetivo apresentar uma revisão da metodologia utilizada na obtenção automática de representações gráficas espaciais em geociências, bem como propor algumas técnicas alternativas à metodologia corrente, de acordo com os resultados apresentado na dissertação de Mestrado do autor. (Yamamoto 1986).

A interpolação é, sem dúvida, a fase de maior importância na obtenção de representações gráficas em computador, seja ela empregada para regularizar uma malha de amostragem irregular como também para enriquecer uma malha originalmente regular para traçado suave das curvas de contorno. Assim, dada a importância da interpolação em procedimentos gráficos, deu-se bastante ênfase na apresentação e na discussão dos principais métodos existentes em Geologia.

A aplicação das principais formas de representação gráfica espacial será exemplificada com dados de topografia da região e também com os dados de análises químicas de elementos maiores das rochas do Complexo Alcalino de Anitápolis (SC). Com os primeiros, pretende-se exemplificar a obtenção de mapas de contorno e blocos-diagramas, que são as formas de representação gráfica quantitativa e qualitativa, respectivamente, mais utilizadas para dados distribuídos em área. Os dados de análises químicas serão utilizados no mapeamento tridimensional da jazida, isto é, a representação gráfica da variação espacial ao longo da mesma, por meio de perfis e plantas.

MÉTODOS As representações gráficas espaciais mais comuns podem ser obtidas conforme o fluxo de processamentos apresentado na figura 1.

Esse fluxograma foi idealizado para desenho automático das figuras espaciais a partir de uma malha regular de dados, seja ela bi ou tridimensional. Essa decisão foi tomada após uma pesquisa bibliográfica que apontou o desenho automático a partir de malhas regulares como o mais indicado para a obtenção de um melhor produto final, em termos estéticos bem como as facilidades computacionais advindas da utilização das mesmas. Dificilmente, porém, as investigaçōes em geociências resultam em dados distribuídos sobre uma malha regular, e, sim, distribuídos irregularmente na região pesquisada devido, principalmente, a problemas de vias de acesso. Uma exceção seria, por exemplo, uma campanha de sondagens planejada sobre uma malha regular; entretanto, o detalhamento de algumas

\footnotetext{
* Artigo de reunião e sintese sobre o tema

** Instituto de Pesquisas Tecnologicas do Estado de São Paulo-IPT, Divisão de Minas e Geologia Aplicada. Cidade Universitária, Caixa Postal 7141, CEP 01.000, São Paulo, SP, Brasil
} 


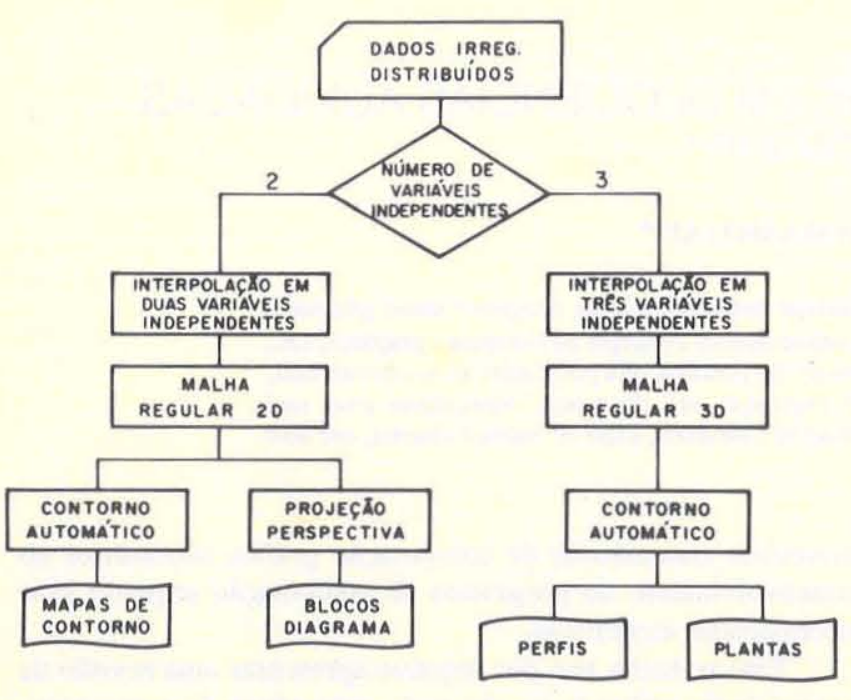

Figura 1 - Fluxo de processamentos para a obtenção de representações gráficas espaciais em Geociências

zonas anômalas numa fase posterior da pesquisa mineral tornaria a malha original irregular. Portanto, pode-se generalizar que será sempre necessário obter-se uma malha regular a partir dos dados originalmente distribufdos sobre uma malha irregular. A regularização dos dados é feita pela interpolação, que é uma técnica de ajuste de uma função matemática aos dados originais para cálculo de valores em pontos não amostrados ou desconhecidos.

O contorno automático é a fase seguinte à da interpolaçãao e permite obter automaticamente mapas de contorno, perfis e plantas em traçadores digitais (plotters), a partir das informações contidas nas células da malha regular.

Os dados da malha regular podem ser projetados em perspectiva, permitindo, assim, visualizá-los em três dimensões. Nesta fase obtêm-se blocos-diagramas, que permitem o estudo das inter-relaçōes espaciais dos parâmetros geologicos.

A notação a ser utilizada para designar as variáveis é a seguinte:

$\mathrm{X}$ ê a variável independente que representa a coordenada leste-oeste;

Y é a variável independente que representa a coordenada norte-suk

$\mathrm{Z}$ é a variável independente que representa a cota; $\mathrm{e}$

F é a variável dependente (pode representar, por exemplo, dados sedimentológicos, geoquímicos, geofísicos etc.).

A origem do sistema de coordenadas é o canto inferior esquerdo, conforme mostra a figura 2 .

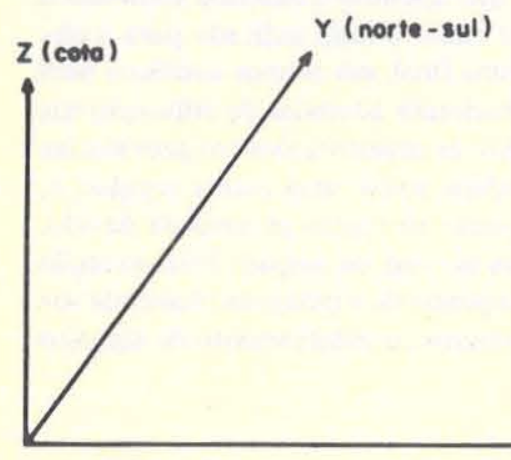

Figura 2 - Sistema de coordenadas geográficas
O primeiro passo na obtenção de representações gráficas espaciais auxiliadas por computador é a definição da geometria da malha regular que é superposta aos pontos de dados amostrados. Sendo esta regular, basta definir a origem, a abertura em cada uma das direçōes (variáveis independentes) bem como o número de nós nas mesmas. $\mathrm{O}$ problema resume-se basicamente na definição da abertura a ser utilizada para cada uma das direções, que pode ser feita tanto empiricamente pelo pesquisador, como numericamente a partir das informações dos pontos de dados.

Esta última maneira apresenta pelo menos dois métodos para cálculo da abertura.

$\mathrm{O}$ primeiro deles é baseado no conceito da distância média, calculada, de acordo com IBM (1965), pela equação (1) a seguir:

$\mathrm{DMED}=[(\mathrm{XMAX}-\mathrm{XMIN}) *(\mathrm{YMAX}-\mathrm{YMIN}) / \mathrm{N}]^{1 / 2}(1)$

em que: DMED é a distância média

XMAX é a coordenada leste-oeste máxima XMIN é a coordenada leste-oeste mínima YMAX é a coordenada norte-sul máxima YMIN é a coordenada norte-sul mínima $\mathrm{N}$ é o número total de pontos de dados

Assim, as aberturas da malha nas direçöes $\mathrm{X}$ e $\mathrm{Y}$, respectivamente DX e DY, são tal que satisfazem à seguinte inequação (2):

$$
\mathrm{DMED} / 4 \leqslant \mathrm{DX} \text { e DY } \leqslant \mathrm{DMED} / 2
$$

O último método baseia-se no conceito geoestatístico da zona de inlfluência (Journel \& Huijbregts (1978) definida sobre o semivariograma dos pontos de dados calculado na direção de interesse. As aberturas DX e DY da malha regular são então definidas pelas amplitudes determinadas da interpretação dos variogramas calculados, respectivamente nas direções $\mathrm{X}$ e Y.

A definição da área de interesse ê de importância fundamental para a utilização correta e confiável das interpolações, pois estas só são válidas dentro do domínio dos pontos de dados amostrados.

A esta área de interesse denomina-se fronteira convexa. Segundo Eddy (1977), a fronteira convexa de um conjunto planar é o polígono convexo de área mínima que engloba o conjunto planar.

Entre os diversos métodos de determinação de fronteiras convexas existentes, Graham (1972), Jarvis (1973), Eddy (1977), Bykat (1978), Green \& Silverman (1979), McCallum \& Avis (1979) e Preparata (1979), entre outros, adotou-se o proposto por Eddy (1977). Segundo esse método, define-se uma linha de partição inicial que une dois pontos quaisquer; por simplicidade, escolhem-se os pontos em coordenadas $\mathrm{X}$ mínima e máxima. Excluem-se esses dois pontos, que já pertencem à fronteira convexa, do conjunto planar original e procede-se à partição. Dessa partição têm-se dois subconjuntos de pontos, denominados, respectivamente, abaixo e acima da linha de partição. Em cada um desses subconjuntos determinase o ponto mais distante da linha de partição; se existirem pontos dentro dos mesmos, os dois pontos encontrados pertencem à fronteira convexa.

Toma-se o primeiro ponto da linha inicial juntamente com um dos novos pontos da fronteira convexa que irão definir uma nova linha e procede-se à nova partição, obtendo-se dois outros subconjuntos e, conseqüentemente, se existirem pontos dentro desses subconjuntos determinam-se dois novos 
pontos da fronteira convexa. E assim, sucessivamente, o procedimento da partição é repetido até que não existam pontos para serem processados. No final desse processo têm-se identificados os pontos que são os vértices do polígono convexo procurado.

Dessa forma pode-se encontrar a fronteira convexa de um conjunto planar de dados em duas variáveis independentes. Resta agora definir a fronteira convexa para dados distriburdos em três variáveis independentes. Tendo em vista que a extensão do método descrito para três variáveis independentes tornaria o procedimento adotado bastante complicado, optouse por utilizar do mesmo algoritmo de forma iterativa, processando cada nível da matriz 3D como um conjunto planar independente até completar todos os níveis da mesma. Adotou-se essa solução para a determinação da fronteira convexa de conjuntos de dados em três variáveis independentes, uma vez que se mostrou satisfatória para os fins do presente trabalho.

Tendo sido definida a fronteira convexa dos dados, é preciso saber se um determinado ponto, e.g. no da malha regular, está dentro ou fora da mesma. Na literatura pesquisada, foram encontrados dois algoritmos que determinam a posição de um ponto em relação a um polígono. O primeiro desses foi apresentado por Hall (1975) e se baseia na soma dos ângulos formados entre o ponto dado e todos os vértices do polígono. Se esta soma for $\pm 360^{\circ}$, o ponto estará dentro; se a soma for $0^{\circ}$, então o ponto estará fora.

O outro algoritmo proposto por Anderson (1976) conta o número de intersecções da reta, que é traçada à direita do ponto e paralela ao eixo de coordenadas $\mathrm{X}$ com os lados do polígono. Se existir um número par de intersecções, o ponto estará fora.

Esses dois algoritmos foram testados e verificou-se que o primeiro é sempre mais preciso e confiável em relação ao último. O algoritmo de Anderson apresenta falhas, principalmente quando o ponto coincide com um dos vértices do polrgono dado. Assim, no presente trabalho, adotou-se o algoritmo de Hall (1975) para a determinação da posição relativa de um ponto com a área de interesse.

Interpolação A interpolação e feita para se determinar os valores da variável dependente sobre os nós de uma malha regular, a partir dos dados observados, que, em geral, estão irregularmente distribuídos. Nesse sentido, a interpolação é efetuada para regularizar a malha de pontos, pois a distribuição inicial era irregular. A interpolação pode também ser utilizada para enriquecer a malha original, caso os dados já estejam regularmente distribuídos, interpolando-se os valores intermediários à amostragem inicial para melhorar o traçado das curvas de contorno. Neste caso, o problema da interpolação torna-se simples e, geralmente, é resolvido utilizando-se das funções splines bicúbicas (IMSL 1982) ou, então funções baseadas nas estimativas das derivadas parciais sobre os nos da malha regular (Akima 1974).

Utiliza-se aqui o termo interpolação tanto para definir o processo pelo qual $\epsilon$ determinado o valor de uma função (determinística) dentro do domínio dos pontos de dados desta bem como para se estimar o valor de uma funçâo aleatória dentro ou fora do domínio dos pontos de dados amostrados.

Uma outra definição importante está relacionada com a dimensionalidade do problema e o número de variáveis independentes. Assim, uma função em duas variáveis independentes tem sua representação geométrica no espaço tridimensional R3, enquanto uma função definida em três variáveis independentes é representada geometricamente no espaço qua- dridimensional R4. Dessa forma uma superfície tridimensional representada no espaço R3 é interpolada usando funções de duas variáveis independentes e uma superfície quadridimensional e interpolada com funções de três variáveis independentes.

O problema da interpolação para a construção de superfícies suaves, partir dos pontos de dados dispersos, é encontrado freqüentemente em muitas áreas de aplicações científicas, tais como Meteorologia, Geografia, Geologia e Engenharia (Franke \& Nielson 1980).

As funções de interpolação podem ser subdivididas em duas classes (Harbaugh et al. 1977), Moore 1977, Akima 1978, Howarth 1983): funçőes globais e funçōes locais.

As funçōes globais aproximam de uma única vez todos os dados do mapa, permitindo-se interpolar o valor da função em qualquer ponto dentro do domínio dos pontos originais de dados. Segundo Franke (1982), a função global é dependente de todos os pontos de dados e a adição ou a retirada de um ponto de dado ou a mudança de uma das coordenadas de um ponto de dado irá propagar através do domínio de definição da função.

Já as funções locais são definidas para pequenas porções do mapa e assim, sucessivamente, até cobrir toda a área do mapa. Conforme Franke (1982), a alteração de um ponto de dado irá afetar somente os pontos próximos do mesmo dentro de alguma dada distância.

Muitas vezes os métodos locais envolvem o uso de métodos globais sobre pequenas porções, que são então compostas para se obter um interpolante global definido sobre suportes locais (Franke 1982).

Cada uma dessas funções de interpolação pode ser subdividida em interpoladores exatos e aproximados. Diz-se que a interpolação é exata quando o resíduo (diferença entre o valor computado pela função de interpolação e o valor observado) é nulo, e aproximada quando há resíduo.

A escolha do tipo de interpolador depende principalmente da natureza dos dados bem como do tipo de mapa que se deseja obter. Assim, se os dados coletados estão com algum tipo de erro, tanto de localização no campo como de medida do parâmetro, é desejável utilizar-se de interpoladores aproximados que, ao promover uma suavização nos dados, pode minimizar tais erros. Por outro lado, se os dados coletados estiverem livres de erros ou seguirem o comportamento de uma função determinística e se o mapa de contorno for utilizado para cálculos (por exemplo: áreas e volumes) mais precisos, devem-se utilizar os interpoladores exatos.

A malha regular a duas dimensões é obtida por interpolação de dados distribuídos em área enquanto a malha regular a três dimensões é obtida a partir da interpolação de dados distribuídos no espaço. A malha regular a três dimensões é composta por uma série de outras a duas dimensões, dispostas vertical (perfis) ou horizontalmente (plantas), ou segundo as duas. Então a interpolação dessas malhas regulares bidimensionais, segundo direções e níveis prê-especificados (perfis e plantas), é feita considerando-se não só os dados que caem sobre os planos das mesmas mas também os dados que caem dentro de uma zona de influência em torno desses planos. Assim, as funçöes de interpolação devem considerar a terceira variável independente (geralmente a cota) para o cálculo de plantas e/ou perfis que compõem a malha regular tridimensional.

Teoricamente, todas as funções a duas variáveis independentes seriam casos particulares das mesmas a três, com uma delas ausente como, por exemplo, um polinômio que pode ser 
definido a uma, duas e três variáveis independentes, conforme as equações abaixo:

$$
\begin{aligned}
& F=a+b X \\
& F=a+b X+c Y \\
& F=a+b X+c Y+d Z
\end{aligned}
$$

A equação (3) representa uma reta no plano, a equação (4), uma superfície plana em área, enquanto a (5), uma hipersuperfície no espaço. Pode-se mostrar, porém, uma única formula que represente as três equaçôes:

$$
F=\sum_{i=0}^{m} \sum_{j=0}^{m-i} \sum_{k=0}^{m-i-j} c_{i j k} \cdot X^{i} \cdot Y^{j} \cdot Z^{k}
$$

Por exemplo, para o caso de uma reta no plano, tem-se:

$$
F=c_{000} X^{0} Y^{0} Z^{0}+c_{100} X^{1} Y^{0} Z^{0}
$$

ou

$$
\mathrm{F}=\mathrm{c}_{0}+\mathrm{c}_{1} \mathrm{X}
$$

que é exatamente o polinômio da equação (3).

Como será demonstrado a seguir, quase todas as funçőes de interpolação em duas variáveis independentes permitem a expansão para o caso a três variáveis independentes, excetuando-se aquelas funçōes de interpolação que usam redes triangularizadas de dados (Akima 1978, Pettinati 1983), em que a inclusão de mais uma variável independente tornaria o processo extremamente complexo e computacionalmente caro, pois a triangulação no plano já é um procedimento complexo e bastante demorado em termos de tempo de computação.

Neste item pretende-se expor os principais métodos atualmente empregados na interpolação de malhas regulares.

A descrição desses métodos será feita sobre funções de duas variáveis independentes tendo em vista que quase todos os métodos aqui descritos permitem expansão para três variáveis independentes acrescentando-se o termo correspondente à terceira variável.

\section{FUNÇÖES GLOBAIS}

Funções polinomiais As funções polinomiais podem descrever aproximadamente o comportamento de uma superfície qualquer, seja ela topográfica, geologica, geofisica etc.

Inicialmente, os polinômios bivariados foram utilizados em Geologia para ajuste de superfícies de tendência. Nesse sentido, os polinômios utilizados são de baixo grau (geralmente 1 a 8 ) e servem para estudo da tendência de variação regional de um determinado parâmetro geologico. Assim, para estudos de tendência de variação, o ajuste de superfícies polinomiais pode ser entendido como uma regressão linear múltipla de uma variável dependente em função de duas variáveis independentes.

Polinômios bivariados de alto grau (maiores de 10) podem ser utilizados seja para descrever superfícies mais complexas, seja para produzir ajustes mais refinados de uma superfície. Teoricamente, e possível proceder-se ao ajuste de superfícies de graus sucessivamente elevados desde que o número de coeficientes do polinômio seja menor ou igual ao número de pontos de dados. A figura 3 mostra um exemplo de como o aumento do grau do polinômio melhora o ajuste à superfície original de dados.
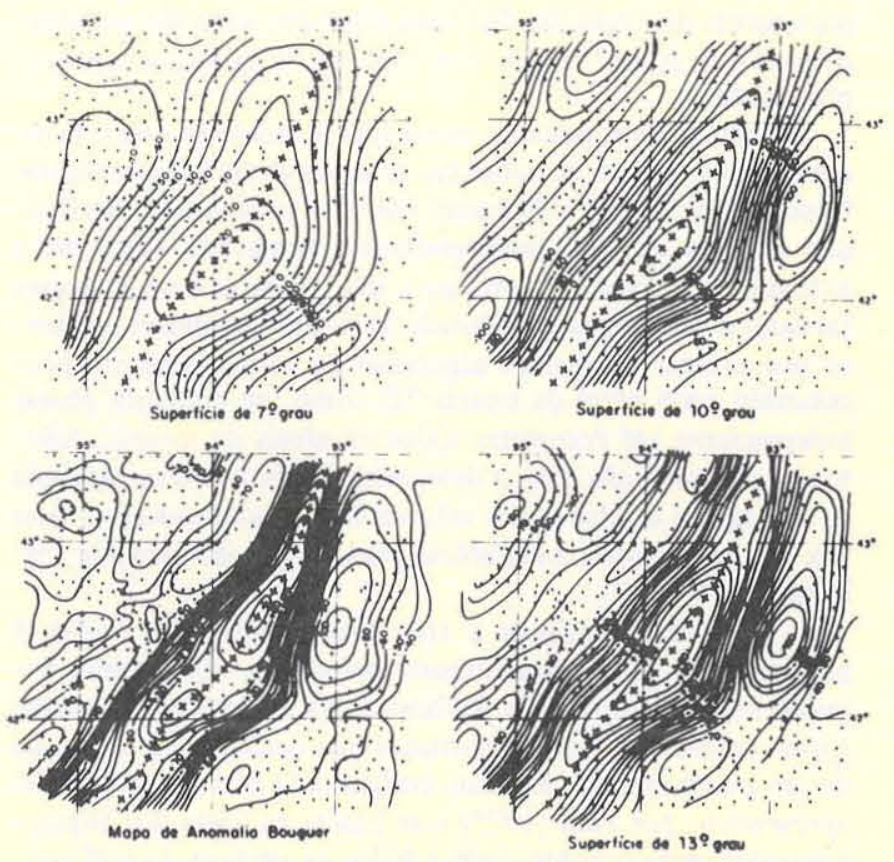

intervalo entre curvas $=10 \mathrm{mgals}$

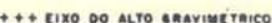

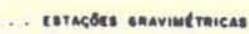

Figura 3 - Mapa de anomalia Bouguer e três superfícies polinomiais de alto grau (Coons et al. 1967, apud Dobrin 1981)

A fórmula geral de um polinômio bivariado de grau m e:

$$
F=\sum_{i=0}^{i} \sum_{j=0}^{m-i} c_{i j} \cdot X^{i} \cdot Y^{j}
$$

em que: F ê a variável dependente

$\mathrm{m}$ é o grau do polinômio

$\mathrm{c}_{\mathrm{ij}}$ são os coeficientes do polinômio

Y é a coordenada norte-sul

$\mathrm{X}$ é a coordenada leste-oeste

O número de coeficientes de um polinômio bivariado de grau m é dado por:

$$
\mathrm{nc}=(\mathrm{m}+1) \cdot(\mathrm{m}+2) / 2
$$

em que: nc ế o número de coeficientes $\mathrm{m}$ é o grau do polinômio

Por exemplo, um polinômio de grau 2, a partir da expansão da equação (9), tem a seguinte forma:

$$
\mathrm{F}=\mathrm{c}_{00}+\mathrm{c}_{01} \mathrm{Y}+\mathrm{c}_{02} \mathrm{Y}^{2}+\mathrm{c}_{10} \mathrm{X}+\mathrm{c}_{11} \mathrm{XY}+\mathrm{c}_{20} \mathrm{X}^{2}
$$

Agrupando-se os termos do mesmo grau obtém-se:

$$
\mathrm{F}=\mathrm{c}_{00}+\mathrm{c}_{10} \mathrm{X}+\mathrm{c}_{01} \mathrm{Y}+\mathrm{c}_{20} \mathrm{X}^{2}+\mathrm{c}_{11} \mathrm{XY}+\mathrm{c}_{20} \mathrm{Y}^{2}
$$

que é a forma mais usual de representação porque dá idéia melhor da expansão dos termos de graus mais baixos para obtenção dos termos de graus mais elevados.

Os coeficientes de um polinômio são determinados pela resolução de um sistema de equações lineares, que satisfaz o 
critério dos mínimos quadrados, ou seja, o polinômio ajustado será tal que a somatória das diferenças ao quadrado entre os valores computados e os valores observados será a mínima possfvel. Por isso as superfícies polinomiais são também chamadas de superficies dos minimos quadrados.

$\mathrm{O}$ sistema de equações lineares, ou também sistema normal de equações, para o cálculo do polinômio da equação (12) tem a seguinte forma matricial:

\begin{tabular}{|c|c|c|c|c|c|c|c|}
\hline $\mathrm{n}$ & $\Sigma x$ & $\Sigma Y$ & $\Sigma \mathrm{X}^{2}$ & $\Sigma X Y$ & $\Sigma X Y$ & $c_{00}$ & $\Sigma F$ \\
\hline$\Sigma x$ & $\Sigma X^{2}$ & $\Sigma X Y$ & $\Sigma X^{3}$ & $\Sigma X^{2} Y$ & $\Sigma X Y^{2}$ & $c_{10}$ & $\Sigma F X$ \\
\hline$\Sigma \mathrm{Y}$ & $\Sigma X Y$ & $\Sigma Y^{2}$ & $\Sigma \mathrm{X}^{2} \mathrm{Y}$ & $\Sigma X Y^{2}$ & $\Sigma Y^{3}$ & $c_{01}=$ & $\Sigma_{F Y}$ \\
\hline$\Sigma \mathrm{X}^{2}$ & $\Sigma X^{3}$ & $\Sigma X^{2} Y$ & $\Sigma X^{4}$ & $\sum X^{3} Y$ & $\sum X^{2} Y^{2}$ & $c_{20}$ & $\sum \mathrm{FX}^{2}$ \\
\hline$\Sigma X Y$ & $\Sigma \mathrm{X}^{2} \mathrm{Y}$ & $\Sigma X Y^{2}$ & ${ }^{2} \Sigma X^{3} Y$ & $\Sigma \mathrm{X}^{2} \mathrm{Y}^{2}$ & $\Sigma X Y^{3}$ & $c_{11}$ & $\Sigma_{F X Y}$ \\
\hline$\Sigma Y^{2}$ & $\Sigma X Y^{2}$ & $\Sigma Y^{3}$ & $\Sigma \mathrm{X}^{2} \mathrm{Y}^{2}$ & $\Sigma X Y^{3}$ & $\sum Y^{4}$ & & $\Sigma F Y^{2}$ \\
\hline
\end{tabular}

A matriz à esquerda da equação (13) é chamada matriz dos produtos escalares e o vetor que a multiplica é o vetor dos coeficientes.

$\mathrm{O}$ vetor $\mathrm{C}$, vetor dos coeficientes, é a única incógnita desse sistema e pode ser obtido a partir da resolução do mesmo, por exemplo, pelo método de eliminação de Gauss (Dorn \& McCracken 1978). O cálculo do vetor C que determina a forma do polinômio, pela equação (13), ilustra como a retirada ou a adição de um único dado irá propagar-se por todo o sistema, como citou Franke (1982).

$\mathrm{O}$ ajuste de superfícies polinomiais de baixo grau, para estudos de tendência de variação, é conhecido em Geologia como análise de superfícies de tendência. Esta análise, no sentido clássico, pressupõe o ajuste de polinômios da forma da equação (9), considerando todos os termos da mesma. Entretanto, segundo Giannini \& Fernandes (1984), muitas das variáveis independentes, termos polinomiais em $\mathrm{X}$ e $\mathrm{Y}$, podem ser mais correlacionáveis entre si que entre as mesmas e a variável dependente. Isso permitiria a eliminação de alguns termos polinomiais já que poderiam ser expressos como combinaçōes lineares de outros. Giannini \& Fernandes (1984) sugerem a aplicação da técnica de regressão múltipla stepwise para ajuste de superfícies de tendência, em que, pelos critérios de correlação e tolerância, procura-se eliminar aqueles termos não significativos dos polinômios que descrevem numericamente a superfície de tendência.

A técnica clássica de análise de superfícies de tendência é feita no sentido de uma regressão polinomial, pelo ajuste de polinômios de graus sucessivamente elevados até encontrar um que produza um ajuste 6 timo. $O$ grau de ajuste 6 timo pode tanto ser definido empiricamente pelo pesquisador como estatisticamente pela análise de variância e teste $\mathrm{F}$.

A análise de variância é feita separando-se da variância total (VT0) a variância explicada (VEX) pela função e a variância não explicada (VNE), devido aos resíduos aleatórios. A figura 4 mostra a seqüência do cálculo das variâncias explicada e não explicada bem como do número $\mathrm{F}$.

\begin{tabular}{|c|c|c|c|c|}
\hline FONTE DE & SOMA DE & GRAUS DE & QUADRADO & NÚMERO F \\
VARIAÇĀO & QUADRADOS & LIBERDADE & MÉDIO & \\
\hline VEX & $\sum\left(\mathrm{FC}_{\mathrm{i}}-\mathrm{F}\right)^{2}$ & $\mathrm{nc}-1$ & $\mathrm{VEX} /(\mathrm{nc}-1)$ & $\mathrm{VEX/(nc-1)}$ \\
VNE & $\sum\left(\mathrm{FC}_{\mathrm{i}}-\mathrm{F}_{\mathrm{i}}\right)^{2}$ & $\mathrm{n}-\mathrm{nc}$ & $\mathrm{VNE} /(\mathrm{n}-\mathrm{nc})$ & $\mathrm{VNE} /(\mathrm{n}-\mathrm{nc})$ \\
VTO & $\sum\left(\mathrm{F}_{\mathrm{i}}-\mathrm{F}\right)^{2}$ & $\mathrm{n}-1$ & & \\
\hline
\end{tabular}

Figura 4 - Análise de variância em que: F E a média dos valores de F observados

$\mathrm{FC}_{\mathrm{i}}$ é o valor de $\mathrm{F}$ computado pela função no ponto $\mathrm{i}$

$\mathrm{F}_{\mathrm{i}}$ é o valor de $\mathrm{F}$ observado no ponto $\mathrm{i}$

nc é o número de coeficintes do polinômio

n ê o número de pontos observados

O número $\mathrm{F}$ assim calculado e, no teste de hipóteses:

$\mathrm{H}_{0}$ : ajuste estatisticamente não significativo

$\mathrm{H}_{1}$ : ajuste estatisticamente significativo

Se o valor do número $\mathrm{F}$ for maior que o valor de $\mathrm{F}$ crítico com nc-1 e n-nc graus de liberdade tomado numa tabela (ver, por exemplo, Pereira \& Bussab 1976), rejeitar-se-á a hipótese $\mathrm{H}_{0}$ e aceitar-se-á a hipótese alternativa $\mathrm{H}_{1}$. Isso pode ser visualizado no gráfico da função $\mathrm{F}$ da figura 5 .

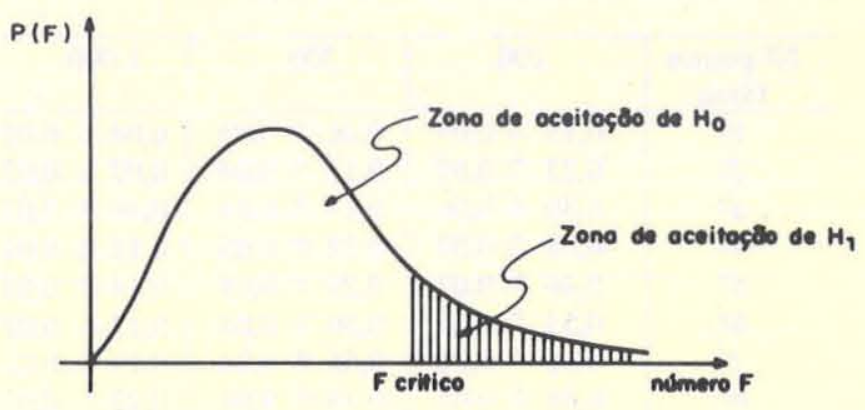

Figura 5 - Gráfico da distribuição $F$ para o teste de hipóteses

Outros parâmetros estatísticos de ajuste podem ser calculados a partir das variâncias:

$$
\begin{aligned}
& \mathrm{CD}=\mathrm{VEX} / \mathrm{VTO} \\
& \text { PSTQ }=\mathrm{CD} .100(\%) \\
& \mathrm{CC}=(\mathrm{CD})^{1 / 2}
\end{aligned}
$$

em que: $C D$ é o coeficiente de determinação

PSTQ é a porcentagem da soma total dos quadrados CC é o coeficiente de correlaçăo

Os dois primeiros parâmetros medem o ajuste propriamente dito da superfície aos pontos originais de dados enquanto o ultimo mede apenas a porcentagem dos pontos que se correlacionam à superfície.

Além da análise de variância, o significado estatístico do ajuste da superfície de tendência pode ser verificado pelo teste dos parâmetros obtidos para a mesma com aqueles de distribuições aleatorias determinados por Amaral (1976).

Amaral (1976) determinou experimentalmente os valores de PSTQ, CC e o número F para distribuiçōes aleatorias com 100,300 e 1.000 pontos, para superfícies de tendência de graus 1 a 8 . Assim, para que a superffcie calculada reflita uma verdadeira tendência de variação, os parâmetros estatísticos obtidos devem ser sempre maiores que aqueles determinados por aquele autor para distribuições aleatórias, conforme as tabelas 1,2 e 3 .

Para superfícies de alto grau, calcula-se apenas os parâmetros estatísticos de ajuste tais como CD, PSTQ e CC. Nesse caso, o ánico cuidado que se deve tomar é quanto ao grau do polinômio, no qual o número de coeficientes deve sempre ser menor que o número de pontos. 
Tabela 1 - Valores em porcentagem da soma total dos quadrados para superfícies de tendência aleatórias (Amaral 1976)

\begin{tabular}{c|r|r|r}
\hline $\begin{array}{c}\text { № pontos } \\
\text { Grau }\end{array}$ & 100 & \multicolumn{1}{|c}{300} & 1.000 \\
\hline $1^{\circ}$ & $2,14 \pm 2,11$ & $0,50 \pm 0,57$ & $0,22 \pm 0,24$ \\
$2^{\circ}$ & $5,62 \pm 3,27$ & $1,45 \pm 0,95$ & $0,55 \pm 0,30$ \\
$3^{\circ}$ & $9,58 \pm 4,07$ & $3,09 \pm 1,42$ & $0,98 \pm 0,45$ \\
$4^{\circ}$ & $14,59 \pm 5,33$ & $4,96 \pm 2,27$ & $1,44 \pm 0,46$ \\
$5^{\circ}$ & $21,68 \pm 6,50$ & $7,10 \pm 2,32$ & $2,06 \pm 0,58$ \\
$6^{\circ}$ & $28,98 \pm 6,99$ & $9,17 \pm 2,42$ & $2,86 \pm 0,81$ \\
$7^{o}$ & $36,55 \pm 7,80$ & $12,16 \pm 2,86$ & $3,64 \pm 0,86$ \\
$8^{\circ}$ & $46,39 \pm 6,44$ & $14,92 \pm 3,00$ & $4,53 \pm 0,99$ \\
\hline
\end{tabular}

Tabela 2 - Valores de coeficientes de correlação para superftcies de tendência aleatorias (Amaral 1976)

\begin{tabular}{c|c|c|c}
\hline $\begin{array}{c}\text { No pontos } \\
\text { Grau }\end{array}$ & 100 & 300 & 1.000 \\
\hline $1^{\circ}$ & $0,13 \pm 0,07$ & $0,06 \pm 0,03$ & $0,04 \pm 0,02$ \\
$2^{\circ}$ & $0,23 \pm 0,07$ & $0,11 \pm 0,04$ & $0,07 \pm 0,02$ \\
$3^{\circ}$ & $0,30 \pm 0,06$ & $0,17 \pm 0,04$ & $0,10 \pm 0,02$ \\
$4^{\circ}$ & $0,38 \pm 0,07$ & $0,22 \pm 0,05$ & $0,12 \pm 0,02$ \\
$5^{\circ}$ & $0,46 \pm 0,07$ & $0,26 \pm 0,04$ & $0,14 \pm 0,02$ \\
$6^{\circ}$ & $0,53 \pm 0,07$ & $0,30 \pm 0,04$ & $0,17 \pm 0,02$ \\
$7^{o}$ & $0,60 \pm 0,06$ & $0,35 \pm 0,04$ & $0,19 \pm 0,02$ \\
$8^{\circ}$ & $0,68 \pm 0,05$ & $0,38 \pm 0,04$ & $0,21 \pm 0,02$ \\
\hline
\end{tabular}

Tabela 3 - Valores do número $F$ para superfícies de tendência aleatorias (Amaral 1976)

\begin{tabular}{c|c|c|c}
\hline $\begin{array}{c}\text { No pontos } \\
\text { Grau }\end{array}$ & 100 & 300 & 1.000 \\
\hline $1^{\circ}$ & $1,08 \pm 1,10$ & $0,75 \pm 0,86$ & $1,08 \pm 1,23$ \\
$2^{\circ}$ & $1,91 \pm 1,18$ & $1,45 \pm 0,96$ & $1,85 \pm 0,99$ \\
3 o & $2,44 \pm 1,22$ & $2,33 \pm 1,12$ & $2,46 \pm 1,14$ \\
$4^{\circ}$ & $2,99 \pm 1,33$ & $3,01 \pm 1,48$ & $2,88 \pm 0,94$ \\
5 o & $3,76 \pm 1,45$ & $3,58 \pm 1,27$ & $3,44 \pm 0,98$ \\
6 o & $4,34 \pm 1,49$ & $3,95 \pm 1,16$ & $4,10 \pm 1,20$ \\
7 o & $4,81 \pm 1,68$ & $4,61 \pm 1,24$ & $4,57 \pm 1,12$ \\
$8^{\circ}$ & $5,46 \pm 1,48$ & $5,01 \pm 1,19$ & $5,05 \pm 1,15$ \\
\hline
\end{tabular}

O erro associado do ajuste de superfícies polinomiais depende tanto do námero de pontos de dados como do grau da função, porque o aumento do grau do polinômio implica o aumento do número de termos do mesmo e, quando este número se aproxima do número de pontos, o ajuste tende a ser exato. Teoricamente, quando o número de termos ou coeficientes do polinômio for igual ao número de pontos de dados, o ajuste será de $100 \%$; entretanto, na prática, isso se torna impossível quando se trabalha com grandes conjuntos de dados.

A extensão das funções polinomiais para o caso a três variáveis independentes ê denominada hipersuperfícies de tendência ou também superfícies de tendência quadridimensionais. A forma geral de uma hipersuperfície de grau $m$ é dada pela equação abaixo:

$$
F=\sum_{i=0}^{m} \sum_{j=0}^{m-i} \sum_{k=0}^{m-i-j} c_{i j k} \cdot X^{i} \cdot Y^{j} \cdot Z^{k}
$$

$\mathrm{O}$ ajuste de hipersuperfícies de tendência bem como a análise do significado estatístico do mesmo são feitos exatamente da mesma forma como da análise de superfícies de tendência.

Segundo Harbaugh \& Merriam (1968), a técnica da análise de hipersuperfícies de tendência proporciona um método conveniente no cálculo de hipervolumes e médias ponderadas espacialmente.

O hipervolume (HYVOL) é obtido calculando-se a integral tripla definida da função $\mathrm{F}(\mathrm{X}, \mathrm{Y}, \mathrm{Z})$ ajustada:

HYVOL $=\int_{X 1}^{X 2} d X \int_{Y 1}^{Y 2} d y \int_{Z 1}^{Z 2} F(X, Y, Z) d Z$

A média ponderada é obtida dividindo-se o hipervolume pelo volume físico definido pelas coordenadas $(\mathrm{X} 1, \mathrm{X} 2) \times(\mathrm{Y} 1, \mathrm{Y} 2) \times(\mathrm{Z} 1, \mathrm{Z} 2)$ :

$$
\overline{\mathrm{F}}=\mathrm{HYVOL} /(\mathrm{X} 2-\mathrm{X} 1) \cdot(\mathrm{Y} 2-\mathrm{Y} 1)-(\mathrm{Z} 2-\mathrm{Z} 1)
$$

O significado geométrico de hipervolumes, bem como de médias ponderadas espacialmente, pode ser visto na figura 6 , que mostra como tais valores podem ser obtidos quando uma, duas e três variáveis independentes estão envolvidas.

Uma média calculada dessa maneira, ponderada espacialmente, ê mais significativa que uma média aritmética convencional, particularmente quando os pontos de dados estão irregularmente distribuídos e contêm extremos. Uma aplicação sugerida é o cálculo do valor da porosidade média de reservatórios de 6́leo em calcários, em que os valores obtidos por análise de testemunhos podem ser altamente erráticos (Harbaugh \& Merriam 1968).

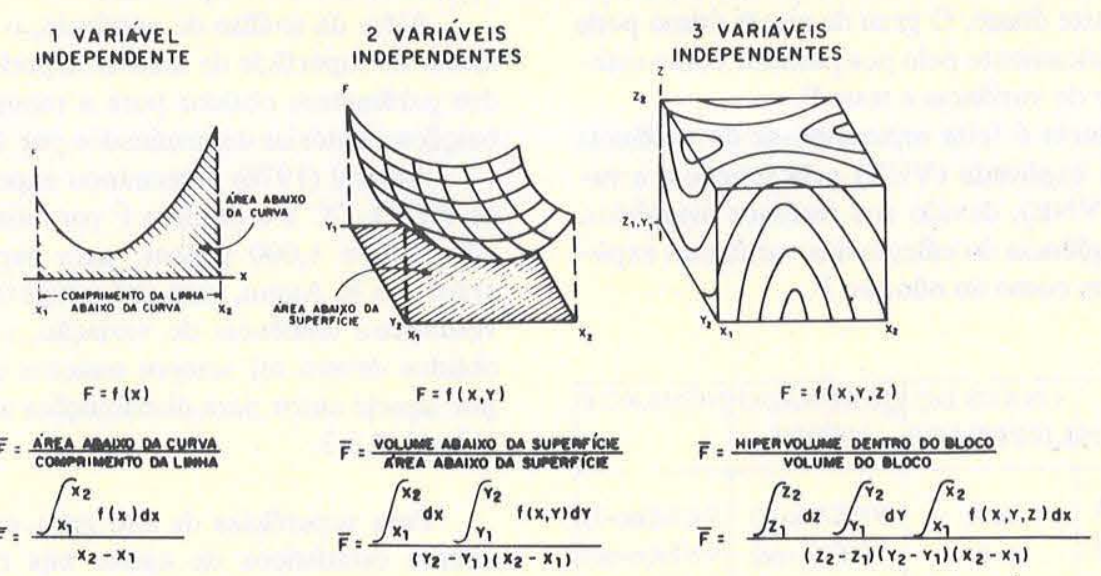

Figura 6 - Diagramas e equações mostrando o cálculo de médias ponderadas espacialmente para uma, duas e três variáveis independentes (segundo Harbaugh \& Merriam 1968) 
Equações multiquádricas Hardy (1971) sugere a aplicação de equações multiquádricas para representação analítica da superfície de um terreno a partir de um conjunto discreto de pontos de observação.

As equações multiquádricas proporcionam uma interpolação exata e foi justamente pesquisada por aquele autor porque os mapas aproximados por polinômios ou harmônicos de Fourier não apresentavam precisão suficiente para fins de Engenharia.

A hipótese básica da análise multiquádrica é que qualquer superfície matemática suave, e também qualquer superfície arbitrária suave (indefinida matematicamente), pode ser aproximada, com o grau de precisão desejado, pela soma de uma grande variedade de superfícies regulares matematicamente definidas, particularmente de formas quádricas (Hardy 1977).

Segundo Franke (1982), o método das equações multiquádricas é o mais impressionante em termos de capacidade de ajuste e suavidade visual entre os diversos métodos de interpolação por ele testados. A forma geral de uma equação multiquádrica é como se segue:

$$
F=\sum_{i=1}^{n} c_{i}\left[\left(X_{i}-X\right)^{2}+\left(Y_{i}-Y\right)^{2}+C\right]^{1 / 2}
$$

em que: $c_{i}$ é o coeficiente da equação multiquádrica

$\mathrm{X}_{\mathrm{i}}$ é a coordenada leste-oeste do ponto $\mathrm{i}$

$\mathrm{Y}_{\mathrm{i}}$ é a coordenada norte-sul do ponto $\mathrm{i}$

$\mathrm{X}$ é a coordenada leste-oeste do ponto a ser interpolado

$\mathrm{Y}$ é a coordenada norte-sul do ponto a ser interpolado

F é o valor da variável dependente interpolada

C ê uma constante que irá definir os termos da superfície multiquádrica

Geometricamente, cada termo da superfície multiquádrica, conforme a equação (20), representa um simples cone, se o valor de $\mathrm{C}$ for igual a zero, ou uma hiberboloide, se o valor de $\mathrm{C}$ for igual a uma constante positiva. Portanto a superfície multiquádrica é representada por uma somatória de cones simples ou hiperboloides, dependendo do valor dado a C. Segundo Hardy (1972), essa somatória tem sido bastante efetiva na representação de vários tipos de topografia.

$\mathrm{O}$ método das equações multiquádricas, de acordo com Franke (1982), é completamente estável em relação à constante C, especificada pelo pesquisador, e dá resultados bastante consistentes.

Hardy (1985) recomenda utilizar ou C igual a zero, ou a valores pequenos, porque se esta constante for grande ocorrerá o mau condicionamento do sistema de equaçōes. Ainda conforme esse autor, um bom valor de trabalho para $\mathrm{C}$ é igual a 0,6 vez o espaçamento entre os pontos dados.

Os coeficientes da equação (20) são obtidos pela resolução de um sistema linear de equações:

$\mathrm{F}=\sum_{\mathrm{j}=1}^{\mathrm{n}} \mathrm{c}_{\mathrm{j}}\left[\left(\mathrm{X}_{\mathrm{j}}-\mathrm{X}_{\mathrm{i}}\right)^{2}+\left(\mathrm{Y}_{\mathrm{j}}-\mathrm{Y}_{\mathrm{i}}\right)^{2}+\mathrm{C}\right]^{1 / 2} \quad$ para $\mathrm{i}=1, \mathrm{n}$

ou em forma matricial, fazendo

$a_{i j}=\left[\left(X_{j}-X_{i}\right)^{2}+\left(Y_{j}-Y_{i}\right)^{2}+C\right]^{1 / 2} \quad$ tem-se

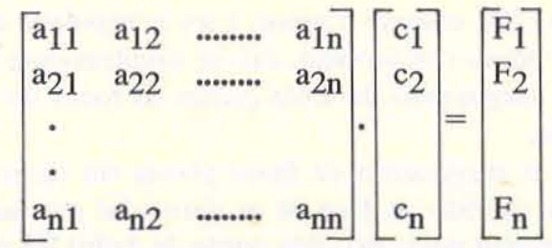

A matriz à esquerda apresenta a diagonal principal igual à raiz quadrada da constante $\mathrm{C}$.

O sistema linear de equações (22) pode ser também resolvido pelo método de eliminação de Gauss (Dorn \& McCracken 1978). Se a constante C for igual a zero, deve-se proceder, antes, à permuta de linhas para que, após essa operação, nenhum elemento da diagonal principal seja nulo. Esse procedimento não altera os valores dos coeficientes.

Uma solução mais eficiente para a resolução do sistema de equações (22) com a diagonal principal nula foi proposta por Hardy (1985). Seguindo sua proposição, ambos os lados do sistema de equações deve ser multiplicado pela matriz dos elementos $\mathrm{a}_{\mathrm{ij}}$. Esta multiplicação deixa os elementos da diagonal principal iguais à soma dos quadrados dos elementos da linha e, portanto, livres de zeros. Assim, após essa operação, o sistema pode ser resolvido normalmente pelo método de eliminação de Gauss.

A principal limitação aqui é a dimensão do sistema porque é sempre igual ao número de pontos. Por exemplo, para 100 pontos de dados, devem-se calcular 100 coeficientes a partir da resolução de um sistema com igual número de equações. Assim, à medida que o número de pontos aumenta, deve-se resolver sistemas lineares cada vez maiores, embora teoricamente seja possível resolver sistemas maiores que o limite de armazenamento de uma matriz em computador (65.635 elementos no computador Burroughs B6900), utilizando-se de partições sucessivas para sistemas menores (Faddeva 1959); entretanto, na prática, o tempo de computação será muito grande, tornando o procedimento inviável.

Segundo Barnhill (1983), a extensão do método das equaçōes multiquádricas para interpolação em três variáveis independentes é direta porque depende somente da medida das distâncias.

Nesse caso, cada termo da equação multiquádrica seria representado geometricamente por uma série de esferas concêntricas ao ponto de dado.

\section{FUNÇÕES LOCAIS}

Ponderação pelo inverso da distância Segundo Franke (1982), o método de interpolação usando a ponderação pelo inverso da distância foi originalmente proposto por Shepard (1968). A formula geral para a interpolação de um ponto com ponderação pelo inverso da potência da distância e:

$$
\mathrm{F}=\sum_{\mathrm{i}=1}^{\mathrm{n}} \mathrm{F}_{\mathrm{i}} \cdot \mathrm{W}_{\mathrm{i}} / \sum_{\mathrm{i}=1}^{\mathrm{n}} \mathrm{W}_{\mathrm{i}}
$$

em que: $\mathrm{F}$ é o valor interpolado

$F_{i}$ É o valor observado no ponto $i$

$\mathrm{W}_{\mathrm{i}}=1 / \mathrm{D}_{\mathrm{i}}^{\mathrm{P}}$ é o ponderador onde:

$\mathrm{D}_{\mathrm{i}}=\left(\left(\mathrm{X}_{\mathrm{i}}-\mathrm{X}\right)^{2}+\left(\mathrm{Y}_{\mathrm{i}}-\mathrm{Y}\right)^{2}\right)^{1 / 2}$ é a distância entre o ponto $\mathrm{i}$ e o ponto a ser interpolado

p ế a potência da distância

n ê o número de pontos dentro da vizinhança ao ponto a ser interpolado 
Na equação (23), quando o ponto a ser interpolado coincidir com algum ponto $\mathrm{i}$ observado, faz-se simplesmente $\mathrm{F}=$ $\mathrm{F}_{\mathrm{i}}$. Isso causa o surgimento de áreas planas ao redor de cada ponto de controle.

Para evitar o surgimento de áreas planas em torno dos pontos de dados (devido ao fato de as derivadas parciais de primeira ordem serem nulas em cada ponto de dado) foi sugerido por Shepard (1968) a inclusão das informações acerca das derivadas na equação (23). Nesse caso a interpolação é feita em dois estágios: onde num primeiro estágio são calculadas as projeções dos mergulhos ou inclinações das superfícies que passam pelos pontos de dados, sobre o ponto a ser interpolado; e, no segundo, calcula-se a média dessas projeções, ponderadas pelo inverso da distância, como sendo o valor interpolado. Esse é o método de interpolação mais utilizado hoje para fins de contorno automático de mapas de isovalores, inclusive naqueles pacotes gráficos comercialmente disponíveis, tais como

- Symap (Dougenick \& Sheeham 1975)

- Surface II Graphics System (Sampson 1975)

$O$ ponderador $(W)$ sendo igual ao inverso de uma potência da distância faz com que o peso seja grande para pontos próximos do ponto a ser interpolado e pequeno para pontos distantes.

A potência da distância também pode ser variada de modo a dar maior ou menor peso para os pontos próximos. Assim, quanto maior for a potência, mais forte será o ponderador, como pode ser visto na figura 7.
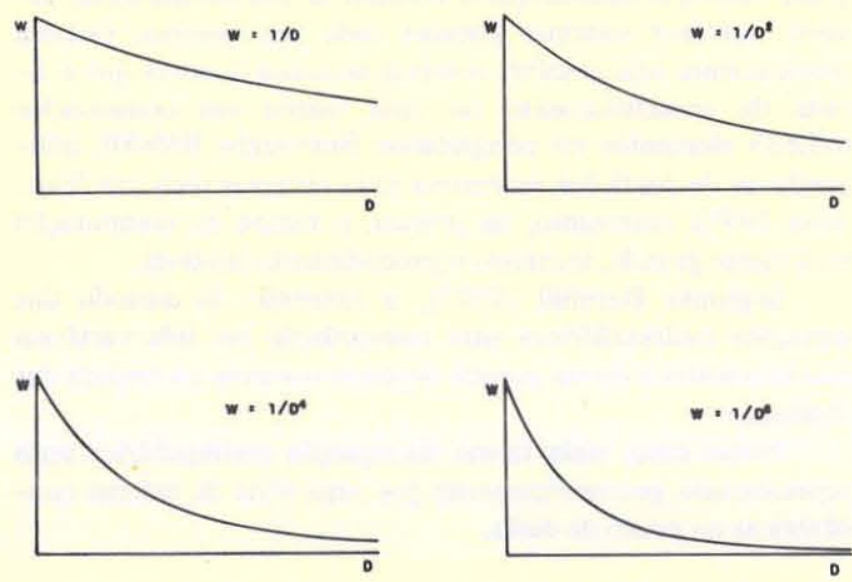

Figura 7 - Funções de ponderação pelo inverso da potência da distância, segundo Sampson (1975)

O erro de interpolação depende, principalmente, da potência da distância e do número de pontos, como pode ser observado nas figuras 8 e 9 , respectivamente.

A extensão do método de Shepard para o caso a três variáveis independentes é bastante utilizada em mineração para fins de cálculo de reservas.

Interpolação em redes triangularizadas A triangulação ê o processo pelo qual o plano XY dos pontos de dados é particionado em triângulos, segundo alguma lei de formação.

Existem várias maneiras de se efetuar a triangulação, porém aquela denominada de Delaunay, conforme Pettinati

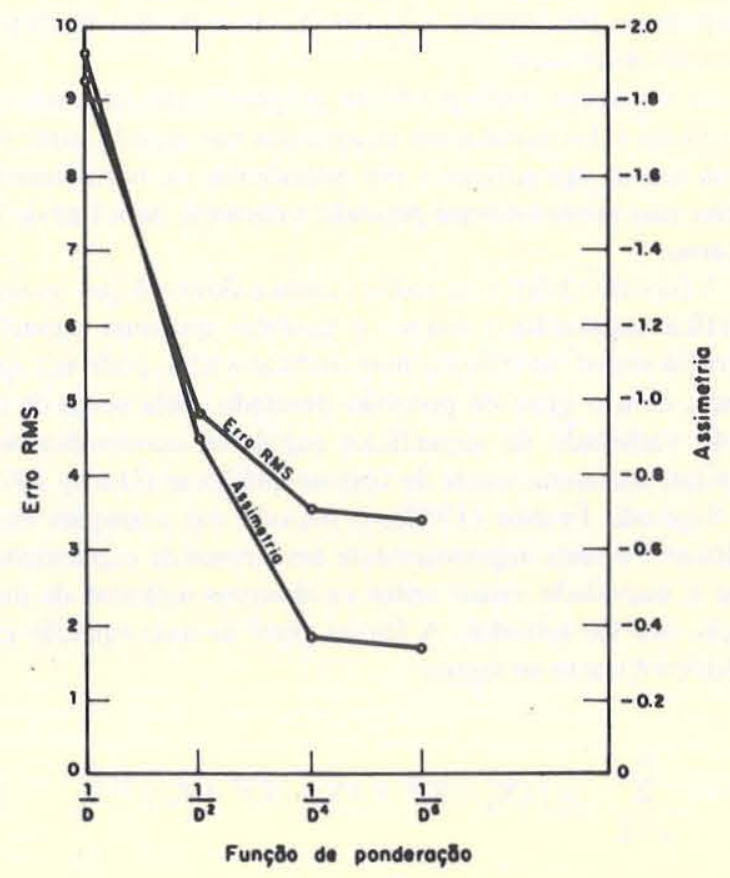

Figura 8 - Erros de interpolação (RMS), usado 8 pontos vizinhos, para diferentes funções de interpolação, segundo Davis (1976, apud Harbaugh et al. 1977)

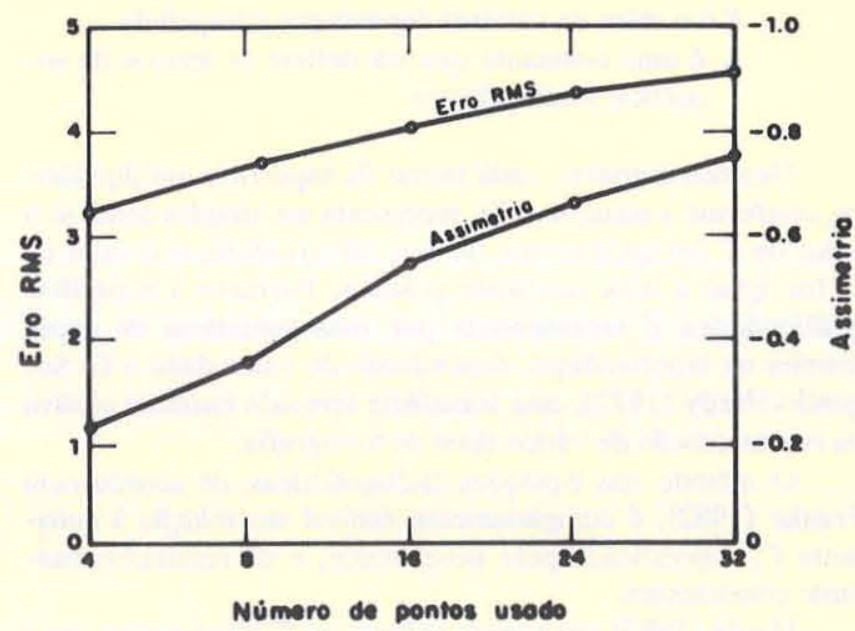

Figura 9 - Erros de interpolação (RMS), para números de pontos vizinhos variáveis, usando a função de ponderação $\left(1 / D^{4}\right)$, segundo Davis (1976, apud Harbaugh et al. 1977)

(1983), ê a mais aceita. Segundo esse autor, a triangulação ê feita a partir da Divisão de Dirichlet, na qual em torno de cada ponto é construído um polígono convexo, de tal modo que dois polígonos contíguos possuam em comum uma única aresta, que $\varepsilon$ eqüidistante dos pontos internos aos referidos poligonos, como pode ser observado na figura 10 . 


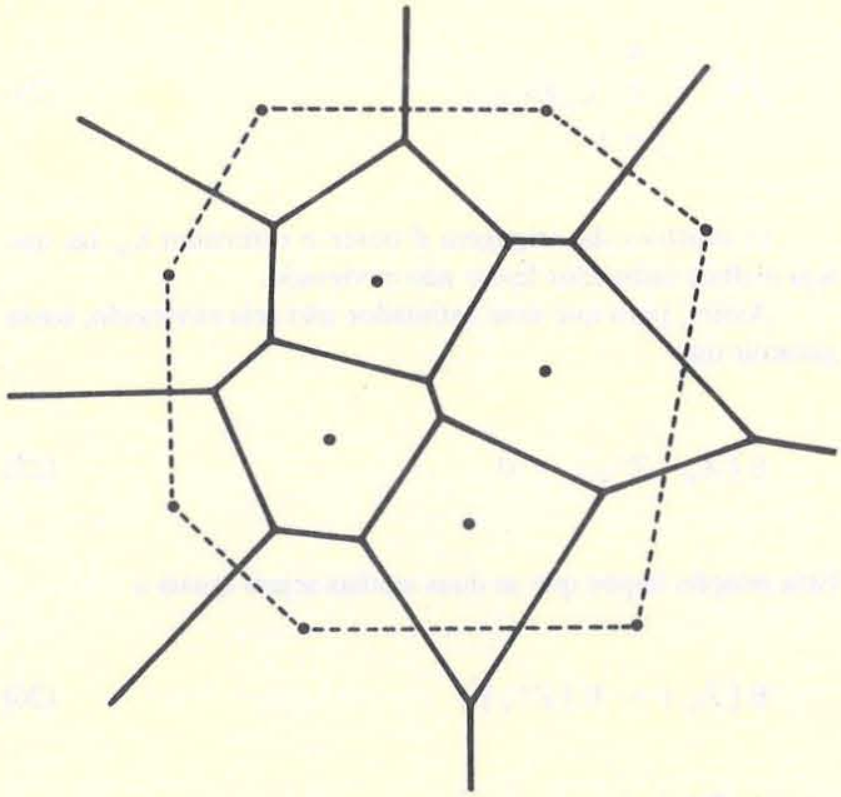

Figura 10 - A divisão de Dirichet, segundo Pettinati (1983)

Ainda conforme o mesmo autor, todos os pontos contíguos são então unidos por segmentos de retas, dando origem a uma malha triangularizada, que é conhecida como Triangulação de Delaunay (Fig. 11).

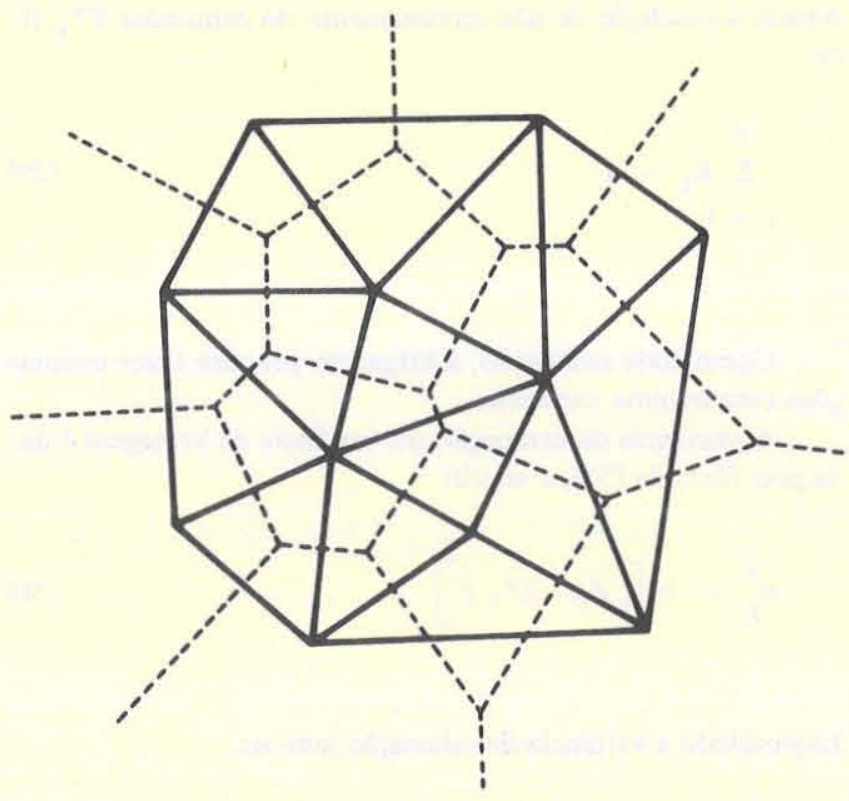

Figura 11 - A triangulação de Delaunay, segundo Pettinati (1983)

Assim, após a obtenção da malha triangular dos dados, a interpolação de um ponto qualquer é feita dentro do domínio da célula triangular a que pertence o mesmo, usando funções matemáticas específicas.

$\mathrm{Na}$ literatura consultada, foram encontrados, basicamente, três métodos que permitem fazer a interpolação em células triangulares.
O primeiro deles é o mais simples, porque ajusta um plano em cada triângulo, usando as informaçőes dos três vértices, e faz-se uma interpolação linear (Bengtsson \& Nordbeck 1964, Watson 1982).

O segundo já é mais refinado em relação ao anterior e a interpolação é feita a partir do cálculo de ponderadores associados a cada vértice do triângulo (McLain 1976, Franke \& Nielson 1980, gold et al. 1977). No cálculo desses ponderadores estão implícitas condições que grantem suavidade e continuidade lateral nos triângulos vizinhos. Na figura 12 tem-se uma comparação das superfícies obtidas para um mesmo conjunto de dados usando os dois métodos descritos anteriormente.
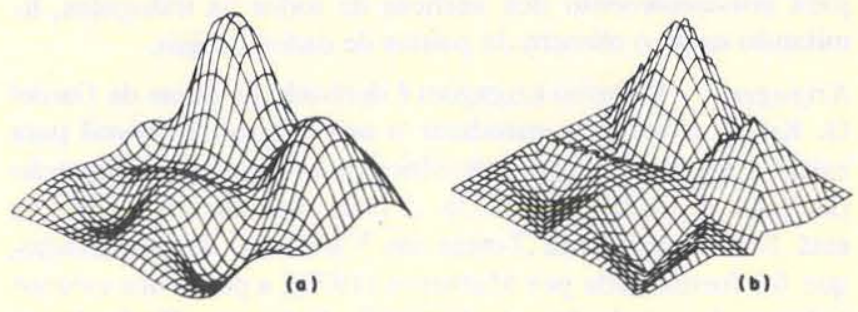

Figura 12 - Superfícies obtidas pelo método dos ponderadores (a) e por interpolação linear (b), conforme McLain (1976)

O último método faz a interpolação a partir do ajuste de uma superff́cie de grau 5 em cada triângulo (Akima 1978, Pettinati 1983). Como um polinômio de grau 5 tem 21 coeficientes, enquamto o triângulo fornece apenas três informações, ficam restando 18 informaçöes adicionais para que o sistema possa ser resolvido.

Akima (1978) propôs o cálculo das derivadas parciais de primeira e segunda ordens nos vértices do triângulo e as derivadas normais em cada um dos lados do triângulo.

- para cada vértice: derivadas parciais de primeira ordem (dF/dX e dF/dY);

derivadas parciais de segunda ordem $\left(d^{2} F / d X^{2}, d^{2} F / d Y^{2}\right.$ e d $\left.d^{2} F / d X d Y\right)$

- para cada lado: derivada normal $(\mathrm{dF} / \mathrm{dN})$

que perfazem as 18 condiçōes necessárias para a resolução do sistema. Essas 18 condições adicionais garantem a suavidade $e$ a continuidade da superfície ajustada.

O desempenho desse último método, segundo Franke (1982), depende, principalmente, das estimativas das derivadas parciais. Conforme esse mesmo autor, o algoritmo de Akima é o mais rápido por ele testado, mas dá resultados ruins em alguns casos devido, geralmente, às estimativas também ruins das derivadas parciais e, algumas vezes, devido a triângulos longos e afinados da malha triangularizada.

Segundo Akima (1978), esse método deve ser aplicado somente quando os valores de $\mathrm{F}$ forem precisos ou quando os erros porventura existentes sejam negligenciáveis, porque a interpolação é exata (não há suavização de dados).

Embora a interpolação em redes triangularizadas seja local, a triangulação dos dados é feita de uma única vez e envolvendo todos os pontos de dados. Assim, a retirada ou a adição de um único ponto de dado poderá influir no desenho final da rede de triângulos e, conseqüentemente, no resultado da interpolação. 
Esse método também é expansível para interpolação em três variáveis independentes. Neste caso, a interpolação é feita dentro de tetraedros em vez de triângulos, como no caso a duas variáveis independentes.

O método para interpolação usando a triangulação em três variáveis independentes foi pesquisada por Barnhill (1983) e ao que parece é feita da mesma forma como aquele proposto por Akima (1978), para interpolação de dados irregularmente distribuídos em duas variáveis independentes, ou seja, a triangulação no espaço gera tetraedros dentro dos quais E feita a interpolação a partir das estimativas das derivadas parciais. Segundo Barnhill (1983), alguns problemas ocorrem na triangulação dos dados, na qual a expansão do caso a duas para três variáveis independentes não e tão simples.

Em termos computacionais, o algoritmo deve ser bastante complexo e exigindo também grande espaço da memória para armazenamento dos vértices de todos os triângulos, limitando assim o número de pontos de dados iniciais.

Krigagem $\mathrm{O}$ termo krigagem é derivado do nome de Daniel G. Krige, pioneiro a introduzir o uso de médias móveis para evitar a superestimação sistemática de reservas em mineração (Delfiner \& Delhomme 1975). A base conceitual da krigagem está fundamentada na Teoria das Variáveis Regionalizadas, que foi formalizada por Matheron (1971), a partir dos estudos práticos desenvolvidos por Daniel G. Krige no cálculo de reservas na minas de ouro do Rand na África do Sul.

A aplicação da Teoria das Variáveis Regionalizadas para estimação de depósitos minerais recebe o nome de Geoestatística (Matheron 1971).

O cálculo do teor médio para um bloco de jazida, a partir dos dados de teores obtidos nas amostras coletadas ao longo dos furos de sondagem, é um problema de estimação. A krigagem é um método geoestatístico de estimação que usa as informações dos pontos vizinhos, considerando não só os valores de teor mas também a posição espacial relativa dos mesmos.

Segundo Brooker (1979), as técnicas de estimação geoestatísticas, baseadas no estudo da variabilidade espacial do corpo de minério pelo semivariograma, são superiores porque permitem o cálculo do erro associado às estimativas, chamado variância de estimação. Ainda conforme o mesmo autor, a krigagem é o procedimento que permite calcular os ponderadores para uma dada configuração (bloco $\mathrm{x}$ disposição das amostras no espaço) com mínima variância de estimação. A

A krigagem, originalmente desenvolvida para fins de estimação de reservas, pode também se utilizada na interpolação de malhas regulares para fins de contorno automático, conforme algumas aplicações apresentadas por Delfiner \& Delhomme 1975, Sampson 1975, Burguess \& Webster 1.980 a e b. Neste item, desenvolvem-se os aspectos teóricos da krigagem, que é aplicada a fenômenos estacionários. Para fenômenos não-estacionários e, portanto, que apresentam uma certa tendência (deriva), aplica-se a krigagem universal, na qual a componente de tendência é removida pelo ajuste de uma função polinomial, geralmente de baixo grau, e os resíduos são tratados de maneira semelhante à da krigagem. Olea (1975) e Webster \& Burguess (1980) tratam especificamente da kriagem universal aplicada a problemas de interpolação de superfícies.

Assim, a krigagem pode ser utilizada para se estimar o valor desconhecido $Z_{V}$, sobre o nó de uma malha regular, a partir de um conjunto de $n$ pontos dados $Z\left(x_{i}\right), i=1$, $n$, vizinhos ao nó. O estimador $\mathrm{Z}^{*} \mathrm{y}$, associado a cada nó da malha regular a ser interpolada, é obtido como uma combinação linear dos n pontos dados, conforme a formula a seguir:

$$
\mathrm{Z}^{*}{ }_{\mathrm{v}}=\sum_{\mathrm{i}=1}^{\mathrm{n}} \lambda_{\mathrm{i}} \mathrm{Z}\left(\mathrm{x}_{\mathrm{i}}\right)
$$

O objetivo dą krigagem é obter o estimador $\lambda_{i}$, tal que seja melhor estimador linear não enviesado.

Assim, para que esse estimador não seja enviesado, basta garantir que

$$
\mathrm{E}\left[\mathrm{Z}_{\mathrm{V}}-\mathrm{Z}^{*}{ }_{\mathrm{v}}\right]=0
$$

Esta relação impõe que as duas médias sejam iguais a

$$
\mathrm{E}\left[\mathrm{Z}_{\mathbf{v}}\right]=\mathrm{E}\left[\mathrm{Z}^{*} \mathbf{v}\right]
$$

fazendo $\mathrm{E}\left[\mathrm{Z}_{\mathrm{V}}\right]=\mathrm{m}$ e tendo que

$$
\begin{aligned}
& E\left[Z^{*}{ }_{v}\right]=E\left[\sum_{i=1}^{n} \lambda_{i} Z\left(x_{i}\right)\right]=\sum_{i=1}^{n} \lambda_{i} E\left[Z\left(x_{i}\right)\right] \\
& E\left[Z^{*}{ }_{v}\right]=m \sum_{i=1}^{n} \lambda_{i}
\end{aligned}
$$

Assim, a condição de não enviesamento do estimador $Z^{*}{ }_{v}$ fica:

$$
\sum_{i=1}^{n} \lambda_{i}=1
$$

Como toda estimação, a krigagem procura fazer estimações com mínima variância.

A variância de estimação ou variância de krigagem é dada pela formula (30), a seguir:

$$
\sigma_{E}^{2}=E\left[\left(Z_{v}-Z_{v}^{*}\right)^{2}\right]
$$

Expandindo a variância de estimação tem-se:

$$
\sigma_{\mathrm{E}}^{2}=\mathrm{E}\left(\mathrm{Z}_{\mathrm{v}}^{2}\right)-2 \mathrm{E}\left(\mathrm{Z}_{\mathrm{v}} \mathrm{Z}^{*}{ }_{\mathrm{v}}\right)+\mathrm{E}\left(\mathrm{Z}^{*} \mathrm{v}^{2}\right)
$$

Sendo conhecida a estimativa de um valor médio sobre um domínio $\mathrm{V}$, conforme relação a seguir:

$$
E\left(Z_{v}\right)=\frac{1}{V} \int_{V} Z(x) d x
$$


a equação (31) torna-se:

$$
\begin{aligned}
& \sigma_{E}^{2} \frac{1}{V^{2}} \int_{V} d x \int_{V} E\left[Z(x) Z\left(x^{\prime}\right)\right] d x- \\
& 2 \underset{\alpha \alpha \alpha}{\sum_{\alpha}} \frac{1}{\mathrm{Vv}_{\alpha}} \int_{V^{\prime}} d x \int_{\alpha} E\left[Z(x) z\left(x^{\prime}\right)\right] d x^{\prime}+ \\
& +\sum_{\alpha \beta} \sum_{\beta} \lambda_{\alpha} \lambda_{\beta} \frac{1}{v_{\alpha} v^{v}} \int_{v_{\alpha}} d x \int_{v_{\beta}} E\left[Z(x) Z\left(x^{\prime}\right)\right] d x^{\prime}
\end{aligned}
$$

Dentro do sinal de integração mais interno, o termo $\mathrm{E}\left[\mathrm{Z}(\mathrm{x}) \mathrm{Z}\left(\mathrm{x}^{\prime}\right)\right]$ pode ser referido em termos da co-variância:

$E\left[Z(x) Z\left(x^{\prime}\right)\right]=C(h)+m^{2}=C\left(x-x^{\prime}\right)+m^{2}$

Substitundo-se (34) em (33) tem-se:

$$
\begin{aligned}
& \sigma_{E}^{2} \frac{1}{V^{2}} \int_{V} d x \int_{V} C\left(x-x^{\prime}\right) d x^{\prime}+m^{2}- \\
& 2 \underset{\alpha \alpha}{\sum} \frac{1}{v^{2}} \int_{V} d x \int_{v_{\alpha}} C\left(x-x^{\prime}\right) d x^{\prime}-2 m^{2}+ \\
& \left.+\underset{\alpha \beta}{\sum} \lambda_{\alpha} \lambda_{\beta} \frac{1}{v_{\alpha} v_{\beta}} \int_{v_{\alpha}} d x \int_{v_{\beta}} C\left(x-x^{\prime}\right) d x^{\prime}+m^{2} 35\right)
\end{aligned}
$$

Fazendo:

$$
\begin{aligned}
& \bar{C}(V, V)=\frac{1}{V^{2}} \int_{V} d x \int_{V} C\left(x-x^{\prime}\right) d x^{\prime} \\
& \bar{C}\left(V, v_{\alpha}\right)=\frac{1}{V v_{\alpha}} \int_{V} d x \int_{v_{\alpha}} C\left(x-x^{\prime}\right) d x^{\prime}
\end{aligned}
$$

$\bar{C}\left(v_{\alpha}, v_{\beta}\right)=\frac{1}{v_{\alpha} v_{\beta}} \int_{v_{\alpha}} d x \int_{v_{\beta}} C\left(x-x^{\prime}\right) d x^{\prime}$

Substituindo-se (36), (37) e (38) em (35), tem-se a variância de estimação como:

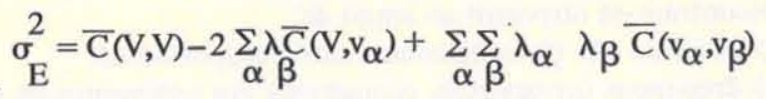

O significado de cada um dos termos $C$ da equação (39) pode ser melhor entendido pela figura 13.

Assim, $\overline{\mathrm{C}}(\mathrm{V}, \mathrm{V})$ é o valor médio da função co-variância entre todos os pares de pontos dentro do volume $\mathrm{V} ; \overline{\mathrm{C}}\left(\mathrm{V}, \mathrm{v}_{\alpha}\right)$ valor médio da função co-variância entre uma amostra $v_{\alpha}$

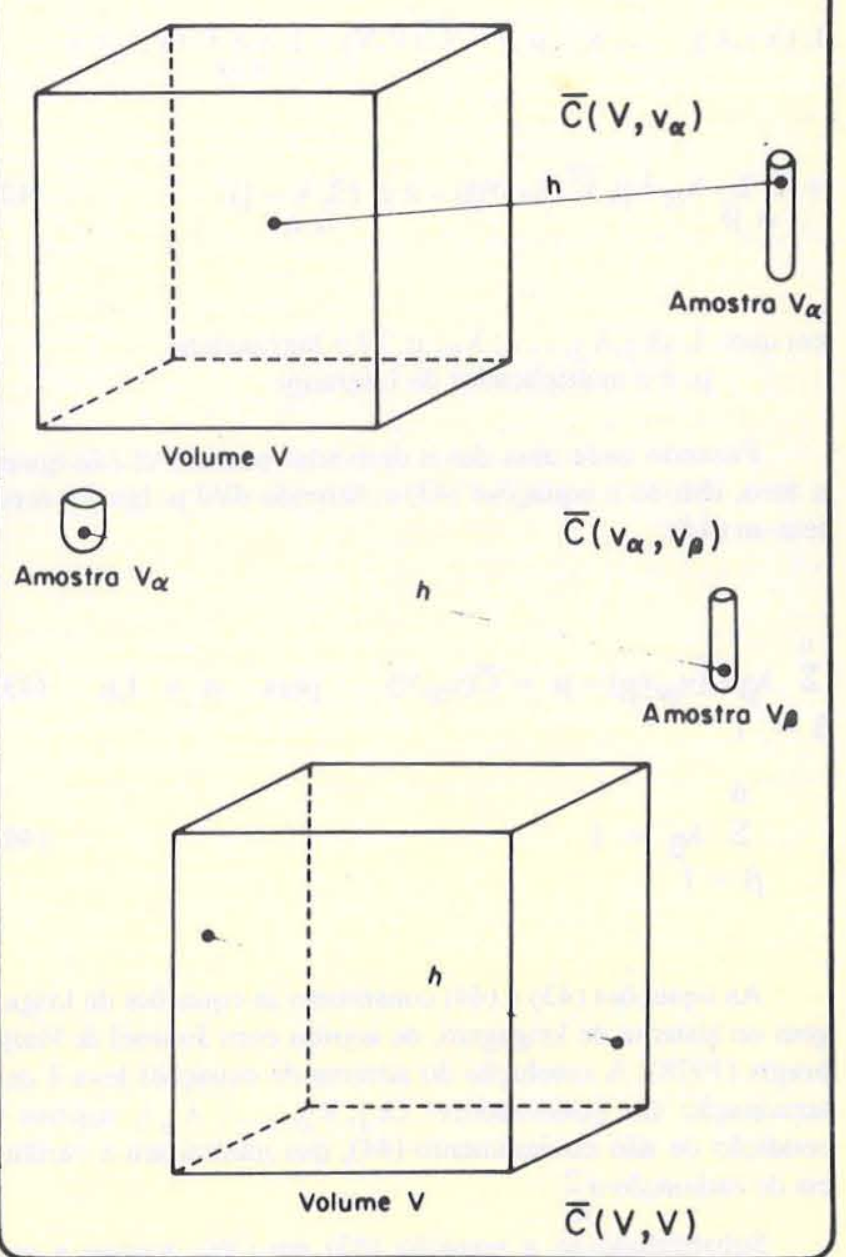

Figura 13 - Significado dos termos equação (39), conforme Brooker (1979)

e todo o volume $\mathrm{V}$, assim calculada para todas as amostras e $\bar{C}\left(v_{\alpha}, v_{\beta}\right)$ é o valor médio da função co-variância entre todos os pares possíveis de amostras $\mathrm{v}_{\alpha}$ e $\mathrm{v}_{\beta}$.

$\mathrm{O}$ objetivo da krigagem é buscar a melhor estimação, ou seja, encontrar o conjunto de ponderadores com mínima variância de estimação ou de krigagem. Trata-se, portanto, de encontrar o mínimo da função variância de estimação [equação (39)]. Entretanto, como tal função tem n variáveis, o ponto mínimo poderá ser determinado após a aplicação da técnica dos multiplicadores de Lagrange (Converse 1970), conforme colocação do problema a seguir:

- minimizar a função:

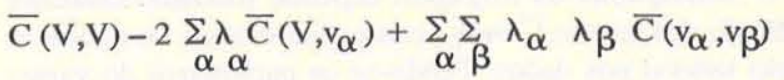

- restrito a:

$$
\underset{\alpha=1}{\sum \lambda_{\alpha}=1} \stackrel{\text { ou }}{\sum} \underset{\alpha=1}{\sum} \lambda_{\alpha}-1=0
$$


Forma-se o lagrangiano

$$
\begin{aligned}
& \mathrm{L}\left(\lambda_{1}, \lambda_{2}, \ldots, \lambda_{\mathrm{n}}, \mu\right)=\overline{\mathrm{C}}(\mathrm{V}, \mathrm{V})-\underset{\alpha \alpha}{2 \lambda_{\alpha} \overline{\mathrm{C}}\left(\mathrm{V}, \mathrm{v}_{\alpha}\right)+} \\
& +\sum_{\alpha \beta} \sum_{\alpha} \lambda_{\beta} \overline{\mathrm{C}}\left(\mathrm{v}_{\alpha}, \mathrm{v}_{\beta}\right)-2 \mu \underset{\alpha \alpha}{\left(\sum \lambda_{\alpha}-1\right)}
\end{aligned}
$$

em que: $L\left(\lambda_{1}, \lambda_{2}, \ldots, \lambda_{n}, \mu\right)$ é o lagrangiano $\mu$ é o multiplicador de Lagrange

Fazendo cada uma das $\mathrm{n}$ derivadas parciais $\mathrm{dL} / \mathrm{d} \lambda$ iguais a zero, têm-se n equações (43) e, fazendo $\mathrm{dl} / \mathrm{d} \mu$ igual a zero, tem-se (44):

$$
\sum_{\beta=1}^{\mathrm{n}} \lambda_{\beta} \overline{\mathrm{C}}\left(\mathrm{v}_{\alpha}, \mathrm{v}_{\beta}\right)-\mu=\overline{\mathrm{C}}\left(\mathrm{v}_{\alpha}, \mathrm{V}\right) \quad \text { para } \quad \alpha=1, \mathrm{n}
$$

$$
\sum_{\beta=1}^{n} \lambda_{\beta}=1
$$

As equações (43) e (44) constituem as equações de krigagem ou sistema de krigagem, de acordo com Journel \& Huijbregts (1978). A resolução do sistema de equações leva à determinação dos ponderadores $\left(\lambda_{1}, \lambda_{2}, \ldots, \lambda_{n}\right)$, sujeitos à condição de não enviesamento (44), que minimizam a variância de estimação $\sigma_{E}^{2}$

Substituindo-se a equação (43) em (39), tem-se a variância de krigagem escrita da seguinte forma:

$$
\underset{\mathrm{E}}{\sigma^{2}}=\overline{\mathrm{C}}(\mathrm{V}, \mathrm{V})+\mu \underset{\alpha=1}{-\sum_{j}^{\mathrm{n}} \lambda_{\beta} \overline{\mathrm{C}}\left(\mathrm{v}_{\alpha}, \mathrm{V}\right)}
$$

O sistema de equações (43) também pode ser escrito em termos da função semivariograma.

$$
\text { n }
$$$$
\sum \lambda_{\beta} \bar{\gamma}\left(v_{\alpha}, v_{\beta}\right)+\mu=\bar{\gamma}\left(v_{\alpha}, \mathrm{V}\right) \text { para } \neq \alpha=1, \mathrm{n}
$$

$\beta=1$

Nesses termos, a variância de krigagem torna-se:

$$
\underset{\mathrm{E}}{\sigma_{\alpha=1}^{2}}=\sum_{\alpha=1}^{\mathrm{n}} \lambda_{\alpha} \bar{\gamma}\left(\mathrm{v}_{\alpha}, \mathrm{V}\right)+\mu-\bar{\gamma}(\mathrm{V}, \mathrm{V})
$$

$\mathrm{O}$ desempenho da krigagem depende fundamentalmente do cálculo dos termos $\overline{\mathrm{C}}$ ou $\bar{\gamma}$, conseqüentemente do ajuste do modelo teórico aos dados. Tendo-se os parâmetros do variograma, os valores $\overline{\mathrm{C}}$ ou $\bar{\gamma}$ podem ser encontrados ou em tabelas pré-calculadas para determinadas geometrias, ou então calculados pelo método de Gauss-Cauchy (Journel \& Huijbregts 1978). O maior problema, portanto, é o ajuste do modelo térico aos dados, que $\varepsilon$, bastante subjetivo. Além disso, o número de pontos de dados é geralmente, muito pequeno para uma estimação confiável do variograma, principalmente para espaçamentos maiores.

Equações multiquádricas definidas sobre suportes locais Este último método de interpolação é uma adaptação para método local das equações multiquádricas, originalmente propostas por Hardy (1971) como global.

Como não havia nenhuma indicação do número de pontos vizinhos e do valor da constante $\mathrm{C}$ a serem utilizados no ajuste local, foram efetuadas várias simulações com superfícies matematicamente conhecidas, a fim de se definirem os parâmetros que pudessem aproximar a superfície original com o menor erro possível. A metodologia empregada bem como os resultados dessas simulações encontram-se apresentados em Yamamoto (1986).

As principais conclusões desse estudo, de acordo com Yamamoto (1986), foram que:

- é viável a utilização de equações multiquádricas como método local para interpolação de dados dispersos em duas e três variáveis independentes;

- a utilização de 12 a 24 pontos vizinhos próximos é um bom compromisso entre a precisão e o tempo de computação requerido;

- não se deve utilizar a constante $\mathrm{C}$ igual a zero e que seu valor deve ser escolhido em função da ordem de grandeza da distância média entre os pontos de dados. Em outras palavras, o ajuste de equações multiquádricas é bastante dependente do sistema de coordenadas escolhido na localização dos pontos de dados (coordenadas numericamente grandes, como, por exemplo, aquelas do sistema UTM, devem ser evitadas e substituídas por valores transformados);

- a utilização de equações multiquádricas para interpolação de dados em três variáveis independentes mostrou-se satisfatoria e, portanto, torna-se um método alternativo aos demais existentes (ponderação pelo inverso da distância e krigagem) para estudo da variação espacial de um determinado parâmetro da jazida.

Métodos para definição da vizinhança próxima Quando se utiliza dos métodos locais de interpolação, além de saber qual o número de pontos a ser utlizado na interpolação é necessário saber também como esses pontos devem ser escolhidos, principalmente em função da distribuição dos pontos de dados na área em estudo.

Segundo Yoeli (1975), são três os tipos de distribuição, dos pontos de dados, possíveis:

- Distribuição aleatória ou dispersa: quando os pontos de dados estão uniformemente distribuídos sobre a área estudada. Esse tipo de distribuição não ocorre com freqüência nas geociências porque, por exemplo, em levantamentos terrestres (prospecção geofísica e geoquímica), depende da existência de vias de acesso e em levantamentos aerotransportados esse tipo de amostragem é economicamente inviável.

- Distribuição semi-regular: quando os pontos amostrados encontram-se dispostos ao longo de:

a) linhas de vôo (levantamentos aerotransportados);

b) drenagens (prospecção geoquímica em sedimentos de corrente);

c) estradas e picadas (reconhecimentos geológicos básicos);

d) seções dispostas irregularmente na área em estudo (investigações sísmicas para obras de engenharia civil).

Como se pôde ver, esse é o tipo de distribuição que deve ocorrer com maior freqüência nas geociências.

- Distribuição regular: quando os pontos de dados estão sobre uma malha regular definida previamente à amostragem (cam- 


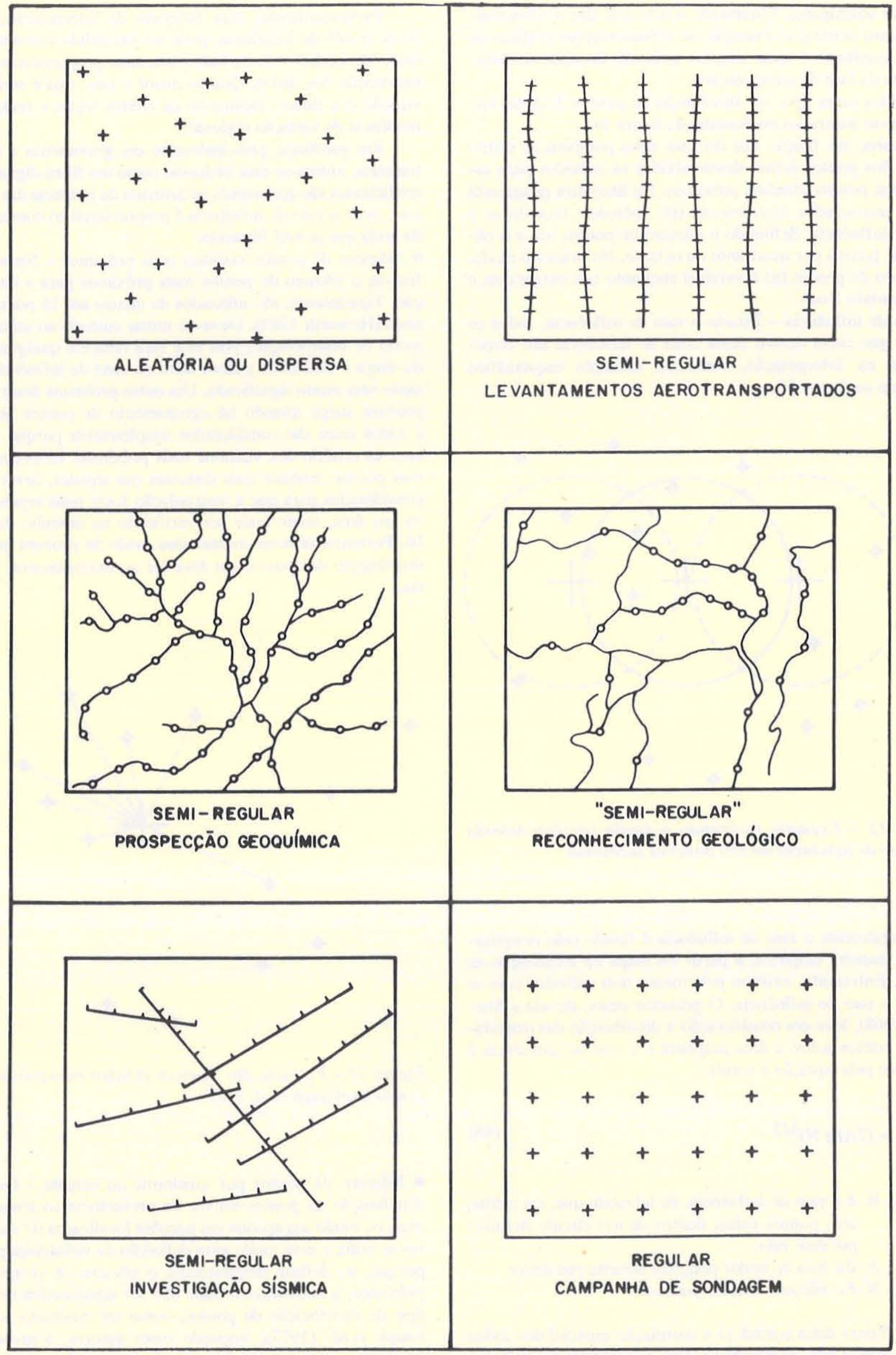

Figura 14 - Tipos de distribuição de dados 
panha de sondagens). Raramente ocorre esse tipo de distribuição e, caso ocorra, a obtenção de representações gráficas de malhas regulares é mais simples, pois não depende necessariamente da fase de interpolação.

Todos esses tipos de distribuição de pontos de dados encontram-se ilustrados no desenho da figura 14.

Assim, em função dos diversos tipos possíveis de distribuição dos pontos foram desenvolvidos os métodos para escolha dos pontos vizinhos próximos. Na literatura pesquisada foram encontrados basicamente três métodos: fixando-se o raio de influência; definindo o número de pontos (n); e o número de pontos por quadrante ou octante. No primeiro modo, o número de pontos (n) é variável enquanto nos outros dois o (n) é mantido fixo.

- Raio de influência - Fixado o raio de influência, todos os pontos que caem dentro dessa zona de influência são considerados na interpolação, conforme exemplo esquemático mostrado na figura 15.

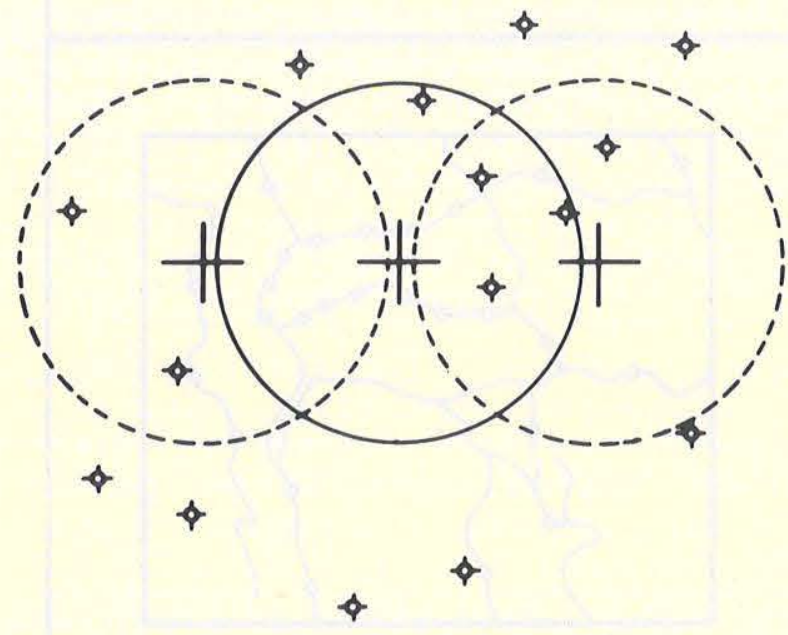

Figura 15 - Esquema mostrando a janela circular definida pelo raio de influência em três posições sucessivas

Geralmente o raio de influência é fixado pelo pesquisador de maneira empírica, a partir do mapa de localização de pontos. Entretanto, existem pelo menos dois métodos para se definir o raio de influência. O primeiro deles, devido a Shepard (1968), leva em consideração a distribuição das densidades de pontos sobre a área mapeada e o raio de influência ê calculado pela equação a seguir:

$$
R=(7 \mathrm{~A} / \pi N)^{1 / 2}
$$

em que: $\mathrm{R}$ é o raio de influência, de tal modo que, em média, sete pontos caiam dentro de um círculo definido por esse raio.

A é a área do maior polígono inscrito nos dados

$\mathrm{N}$ é o número total de pontos

O último deles considera a correlação espacial dos dados e determina o raio de influência igual à amplitude definida sobre o variograma dos dados (Pettinati 1983). A amplitude é a distância que define a vizinhança dentro da qual os pontos são considerados como dependentes.
Particularmente, esse processo de interpolação, fixando-se o raio de influência, pode ser entendido como um processo de médias móveis bidimensionais, proporcionando uma suavização dos dados. Quanto maior o raio, maior será a suavização dos dados, atenuando os efeitos locais e realçando a tendência de variação regional.

Em geofísica, principalmente em gravimetria e magnetometria, utiliza-se esse processo como um filtro digital, cujos coeficientes são justamente os inversos da potência das distâncias, onde o raio de influência é proporcional ao comprimento da onda que se está filtrando.

- Número de pontos vizinhos mais próximos - Nesse modo fixa-se o número de pontos mais próximos para a interpolação. Tipicamente, são utilizados de quatro até 16 pontos vizinhos (Howarth 1983). Deve-se tomar cuidado ao utilizar esse modo de interpolação, pois esta será feita em qualquer ponto do mapa e utilizando pontos além da zona de influência, portanto sem muito significado. Um outro problema desse tipo de procura surge quando há agrupamento de pontos próximos e todos estes são considerados simplesmente porque satisfazem ao critério dos vizinhos mais próximos. Entretanto, outros pontos, embora mais distantes que aqueles, deveriam ser considerados para que a interpolação fosse mais representativa em área, como pode ser verificado no desenho da figura 16. Portanto, deve-se utilizar esse modo de procura quando a distribuição dos pontos em área for aproximadamente aleatória.

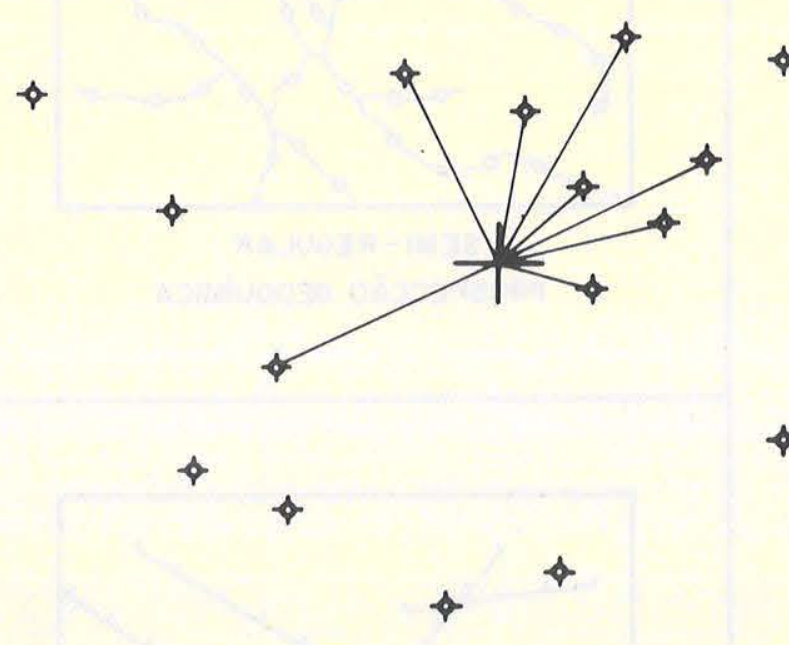

Figura 16 - Pesquisa dos 8 pontos vizinhos mais proximos, segundo Harbaugh et al. 1977

- Número de pontos por quadrante ou octante - Quando a distribuição de pontos estiver de preferência ao longo de linhas ou então agrupados em porções localizadas do mapa, deve-se utilizar esse modo para definição da vizinhança próxima porque, ao definir simplesmente o número de vizinhos mais próximos, a amostragem pode não ser significativa devido ao tipo de distribuição de pontos, como foi mostrado por Harbaugh et al. (1977). Segundo esses autores, a procura por quadrante ou octante é feita dividindo-se a área em torno do ponto a ser interpolado, respectivamente em quatro ou oito setores, e pesquisando-se dentro de cada setor um ou dois pontos mais próximos. As figuras 17 e 18 apresentam, res- 
pectivamente, exemplos de procura dos vizinhos mais proximos utilizando quadrante e octante com os mesmos dados da figura 16. Dessas figuras pode-se ver que os procedimentos de procura por quadrante ou octante proporcionam amostragens mais representativas em área.

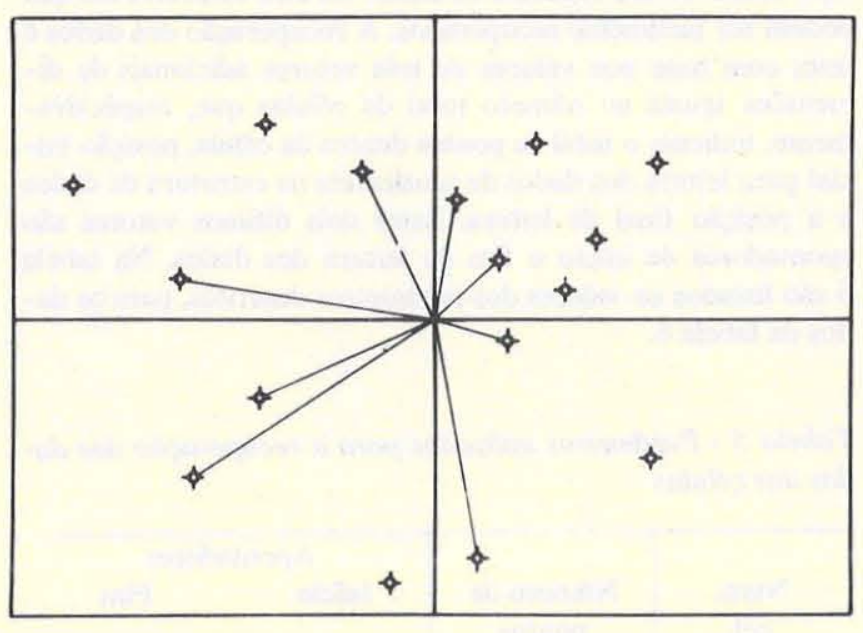

Figura 17 - Pesquisa dos vizinhos mais proximos, tomando 2 pontos por quadrante, segundo Harbaugh et al. 1977

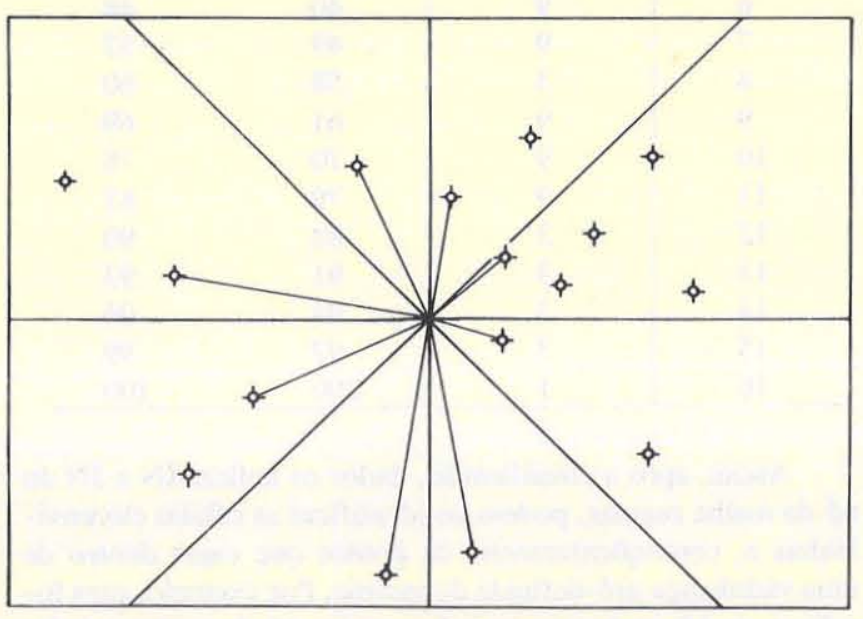

Figura 18 - Pequisa dos vizinhos mais próximos, tomando um ponto por octante segundo Harbaugh et al. 1977

\section{Método para a localização dos pontos vizinhos próxi-} mos No item anterior foram discutidos os tipos possíveis de distribuição dos pontos de dados bem como, em função desses, os métodos para a definição da vizinhança próxima, que procuram fazer uma amostragem espacial significativa. Um outro problema ao se utilizar de funções locais para interpolação de dados é a localização dos vizinhos próximos ao nó da malha a ser interpolado. A localização dos pontos próximos dentro de um arranjo qualquer de dados é muito importante, pois, se a busca for muito demorada, poderá comprometer, em termos de tempo de computação, todo o algoritmo de interpolação que vier a utilizar o método local. A maneira mais simples, porém a menos eficiente, para a localização dos pontos próximos seria medir a distância entre o ponto a ser interpolado e todos os pontos do conjunto de dados, considerando apenas aqueles pontos que caem dentro de alguma distância prefixada. Davis (1973), por exemplo, utiliza-se desse procedimento para a localização dos pontos vizinhos em seu programa de interpolação usando o método Shepard.

O algoritmo desenvolvido por Yamamoto (1986) e descrito a seguir utiliza algumas informaçőes da malha regular, que é superposta aos dados irregularmente distribuídos. A idéia básica desse algoritmo foi procurar os pontos vizinhos dentro das células cincunvizinhas ao nó a ser interpolado.

A figura 19 mostra uma malha regular de 4 x 4 n6s, superposta a um conjunto de 100 pontos de dados gerados aleatoriamente, com origem em $(0,0)$ e abertura igual a $3 \mathrm{em}$ ambos os eixos. As células são então numeradas seqüencialmente do sul para norte e de leste para oeste.

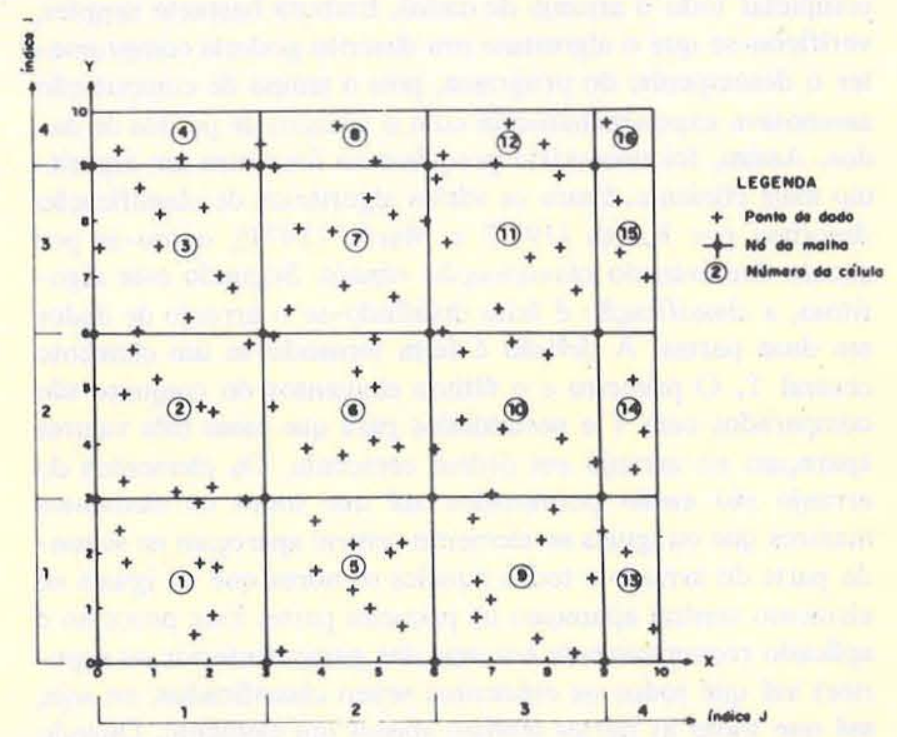

Figura 19 - Mapa de localização dos pontos com a malha regular superposta e a subdivisâo em células

Os pontos de dados lidos pelo programa em qualquer ordem são classificados segundo a seqüência definida para as células. Isso é feito pelo cálculo do número de célula para cada ponto de dado, por meio dos índices $\mathrm{I}$ e $\mathrm{J}$ associados às coordenadas $\mathrm{Y}$ e X, respectivamente, de acordo com as fórmulas a seguir:

$$
\begin{aligned}
& \mathrm{I}=(\mathrm{Y}-\mathrm{YMIN}) / \mathrm{DY}+1 \\
& \mathrm{~J}=(\mathrm{X}-\mathrm{XMIN}) / \mathrm{DX}+1
\end{aligned}
$$

em que: XMIN é a coordenada X mínima YMIN é a coordenada Y mínima DX é a abertura da célula no eixo $\mathrm{X}$

DY é a abertura da célula no eixo Y

Calculados os dois índices, pode-se identificar a célula a que o ponto pertence, usando a seguinte equação:

$$
\mathrm{NCEL}=\mathrm{I}+\mathrm{NY} *(\mathrm{~J}-1)
$$


em que: NY é o número de células no eixo Y NCEL é o número da célula

Os pontos de dados são, então, classificados em ordem crescente do número da célula. A classificação foi feita inicialmente utilizando-se a adaptação de um algoritmo bastante conhecido e denominação informalmente de classificação da bolha (Knuth 1973). O algoritmo original, e como foi descrito por Knuth (1973), classifica os dados em ordem decrescente de "bolhas", porque as bolhas maiores sobem para ocupar as suas verdadeiras posiçőes. Para classificar os dados de um conjunto em ordem crescente, este algoritmo procede da seguinte maneira: toma-se o primeiro elemento do arranjo e o compara com os demais elementos; se existir algum valor menor que o mesmo, faz-se a permuta colocando-o na primeira posição. O procedimento é repetido tomando-se o segundo elemento e procurando-se nos demais valores do arranjo o segundo menor valor do conjunto e assim, sucessivamente, até completar todo o arranjo de dados. Embora bastante simples, verificou-se que o algoritmo ora descrito poderia comprometer o desempenho do programa, pois o tempo de computação aumentava exponencialmente com o número de pontos de dados. Assim, foi necessário pesquisar na literatura um algoritmo mais eficiente. Entre os vários algoritmos de classificação descritos por Knuth (1973) e Martin (1971), optou-se por aquele denominado classificação rápida. Segundo este algoritmo, a classificação é feita dividindo-se o arranjo de dados em duas partes. A div̄isão é feita tomando-se um elemento central T. O primeiro e o último elementos do conjunto são comparados com $\mathrm{T}$ e permutados para que esses três valores apareçam no arranjo em ordem crescente. Os elementos do arranjo são então permutados até que todos os elementos maiores que ou iguais ao elemento central apareçam na segunda parte do arranjo e todos aqueles menores que ou iguais ao elemento central apareçam na primeira parte. Este processo é aplicado recursivamente em uma das partes (inferior ou superior) até que todos os elementos sejam classificados, ou seja, até que todas as partes tenham apenas um elemento. Quando uma parte é finalmente classificada, o processo começa novamente sobre a parte ainda não classificada do arranjo inicial. Para o presente estudo foi utilizada a sub-rotina em FORTRAN IV, que implementa o algoritmo da classificação rápida desenvolvida por Singleton (1969).

A título de ilustração, a tabela 4 apresenta os tempos de execução, em segundos, do computador Burroughs B 6900 , usando os dois algoritmos de classificação aqui descritos para dois conjuntos de pontos de dados gerados aleatoriamente.

Como se pode observar, o tempo de execução do algoritmo de classificação rápida aumenta linearmente com o número de pontos, além de os tempos de execução serem significativamente menores em valores absolutos em relação ao algoritmo de classificação da bolha.

Tabela 4 - Tempos de execução, em segundo, do Burroughs B6900 obtidos para os dois algoritmos de classificação testados

\begin{tabular}{c|c|c}
\hline $\begin{array}{c}\text { Número de } \\
\text { pontos }\end{array}$ & $\begin{array}{c}\text { Classificação } \\
\text { da bolha }\end{array}$ & $\begin{array}{c}\text { Classificação } \\
\text { rápida }\end{array}$ \\
\hline 1.000 & 10,510 & 1,304 \\
5.000 & 277,316 & 6,329 \\
\hline
\end{tabular}

A tabela 5 contém parâmetros que foram obtidos a partir dos dados da tabela 6 . Nesta, são apresentadas as coordenadas dos pontos de dados introduzidas em qualquer ordem, os respectivos índices I e J, o número da célula e novamente as coordenadas classificadas em ordem crescente do número da célula. Como se pode verificar nesta figura, o procedimento aqui desenvolvido organiza os dados em uma estrutura em que podem ser facilmente recuperados. A recuperação dos dados 6 feita com base nos valores de três vetores adicionais de dimensőes iguais ao número total de células que, respectivamente, indicam o total de pontos dentro da célula, posição inicial para leitura dos dados de uma célula na estrutura de dados e a posição final de leitura. Estes dois últimos vetores são apontadores de início e fim de leitura dos dados. Na tabela 5 são listados os valores dos parâmetros descritos, para os dados da tabela 6 .

Tabela 5 - Parâmetros utilizados para a recuperação dos dados das células

\begin{tabular}{r|c|rr}
\hline $\begin{array}{c}\text { Num. } \\
\text { cel. }\end{array}$ & $\begin{array}{c}\text { Número de } \\
\text { pontos }\end{array}$ & \multicolumn{2}{|c}{ Apontadores } \\
Início & Fim \\
\hline 1 & 9 & 1 & 9 \\
2 & 9 & 10 & 18 \\
3 & 9 & 19 & 27 \\
4 & 3 & 28 & 30 \\
5 & 9 & 31 & 39 \\
6 & 9 & 40 & 48 \\
7 & 9 & 49 & 57 \\
8 & 3 & 58 & 60 \\
9 & 9 & 61 & 69 \\
10 & 9 & 70 & 78 \\
11 & 9 & 79 & 87 \\
12 & 3 & 88 & 90 \\
13 & 3 & 91 & 93 \\
14 & 3 & 94 & 96 \\
15 & 3 & 97 & 99 \\
16 & 1 & 100 & 100 \\
\hline
\end{tabular}

Assim, após a classificação, dados os índices IN e JN do nó da malha regular, podem-se identificar as células circunvizinhas e, conseqüentemente, os pontos que caem dentro de uma vizinhança pré-definida do mesmo. Por exemplo, para localizar os 16 pontos mais próximos ao no da malha regular com índices IN e JN iguais a 3, pesquisam-se as quatro células $(6,7,10$ e 11). Na tabela 6 , verifica-se que essas quatro células contêm 36 pontos de dados e, portanto, suficientes para a localização dos 16 pontos mais próximos, que é feita medindo-se a distância entre o nó e todos os 36 pontos de dados e considerando somente os 16 pontos com as menores distâncias. Dessa forma, é possível localizar para qualquer nó da malha regular a vizinhança que contém os pontos mais próximos do mesmo.

Contorno automático Esta é a fase do processamento na qual a malha regular interpolada é pesquisada, segundo algum algoritmo, para produzir as curvas de contorno ou de isovalores em traçadores digitais (plotters).

Os mapas de contorno são a forma de representação gráfica mais usual nas geociências. A interpretação do mapa de isovalores, no caso de dados geológicos, e feita superpondo-se ao mesmo uma base geologica para facilitar as correla- 
ções entre a Geologia e a variação espacial de um determinado parâmetro.

Na literatura consultada pôde-se verificar a existência de vários algoritmos para contorno automático. Entretanto, com a interpolação da malha regular, tais algoritmos ficam restritos a dois tipos:

- O primeiro, denominado método das células (Fig. 20), pes- quisa célula por célula, segundo alguma seqüência preestabelecida, até cobrir toda a malha. Em cada célula, o algoritmo determina todas as interseç̧ões de todas as curvas de contorno que porventura estejam presentes, armazenando-as em uma estrutura de dados. Finalmente, todas as intersecçöes (pares de pontos) de uma determinada curva são recuperadas e desenhadas. Este método foi aperfeiçoado por Pettinati

Tabela 6 - Exemplo ilustrando o algoritmo de classificação para pesquisa dos vizinhos próximos.

\begin{tabular}{|c|c|c|c|c|c|c|c|}
\hline \multicolumn{5}{|c|}{ DADOS NÃO CLASSIFICADOS } & \multicolumn{3}{|c|}{ DADOS CLASSIFICADOS } \\
\hline $\begin{array}{l}\text { Coord. } \\
\text { X }\end{array}$ & $\begin{array}{c}\text { Coord. } \\
\text { Y }\end{array}$ & $\begin{array}{l}\text { Ind. } \\
\text { I }\end{array}$ & $\begin{array}{c}\text { Ind. } \\
\mathrm{J}\end{array}$ & $\begin{array}{l}\text { Num. } \\
\text { cel. }\end{array}$ & \begin{tabular}{|c} 
Coord. \\
X
\end{tabular} & $\begin{array}{c}\text { Coord. } \\
\text { Y }\end{array}$ & $\begin{array}{l}\text { Num. } \\
\text { cel. }\end{array}$ \\
\hline 7,83 & 0,4 & 1 & 3 & 9 & 1,85 & 1,83 & 1 \\
\hline 0,54 & 4,9 & 2 & 1 & 2 & 0,55 & 1,84 & 1 \\
\hline 6,62 & 5,64 & 2 & 3 & 10 & 2,14 & 1,75 & 1 \\
\hline 6,25 & 6 , & 3 & 3 & 11 & 0,16 & 0,03 & 1 \\
\hline 7,45 & 9,74 & 4 & 3 & 12 & 0,42 & 2,41 & 1 \\
\hline 4,39 & 9,72 & 4 & 2 & 8 & 1,73 & 0,52 & 1 \\
\hline 1,63 & 9,14 & 4 & 1 & 4 & 1,83 & 2,9 & 1 \\
\hline 3,77 & 3,91 & 2 & 2 & 6 & 2,68 & 2,95 & 1 \\
\hline 1,22 & 8,12 & 3 & 1 & 3 & 2,07 & 0,86 & 1 \\
\hline 7,21 & 8,99 & 3 & 3 & 11 & 2,08 & 3,22 & 2 \\
\hline 5,38 & 6,62 & 3 & 2 & 7 & 0,71 & 5,69 & 2 \\
\hline 4,59 & 2,13 & 1 & 2 & 5 & 2,13 & 4,59 & 2 \\
\hline 1,91 & 4,69 & 2 & 1 & 2 & 1,91 & 4,69 & 2 \\
\hline 1,12 & 5,17 & 2 & 1 & 2 & 1,12 & 5,17 & 2 \\
\hline 6,29 & 9,16 & 4 & 3 & 12 & 0,54 & 4,9 & 2 \\
\hline 3,91 & 1,67 & 1 & 2 & 5 & 1,45 & 3,13 & 2 \\
\hline 7,02 & 3,02 & 2 & 3 & 10 & 0,51 & 3,33 & 2 \\
\hline 4,29 & 7,78 & 3 & 2 & 7 & 2,79 & 5,78 & 2 \\
\hline 3,29 & 0,2 & 1 & 2 & 5 & 1,2 & 7,52 & 3 \\
\hline 2,79 & 5,78 & 2 & 1 & 2 & 1,22 & 8,12 & 2 \\
\hline 1,73 & 0,52 & 1 & 1 & 1 & 2,01 & 8,23 & 3 \\
\hline 8,33 & 4,07 & 2 & 3 & 10 & 0,86 & 8,59 & 3 \\
\hline 3,02 & 9,38 & 4 & 2 & 8 & 2,51 & 6,8 & 3 \\
\hline 6,78 & 1,46 & 1 & 3 & 9 & 2,28 & 7,01 & 3 \\
\hline 0,42 & 2,41 & 1 & 1 & 1 & 1,71 & 6,28 & 3 \\
\hline 3,5 & 6,4 & 3 & 2 & 7 & 0,8 & 6,04 & 3 \\
\hline 6,56 & 4,38 & 2 & 3 & 10 & 0,13 & 7,51 & 3 \\
\hline 2,81 & 9 & 4 & 1 & 4 & 1,63 & 9,14 & 4 \\
\hline 8,08 & 9,36 & 4 & 3. & 12 & 2,81 & 9 & 4 \\
\hline 3,21 & 5,92 & 2 & 2 & 6 & 0,48 & 9,27 & 4 \\
\hline 4,98 & 4,04 & 2 & 2 & 6 & 3,29 & 0,2 & 5 \\
\hline 0,51 & 3,33 & 2 & 1 & 2 & 4,59 & 2,13 & 5 \\
\hline 8,11 & 5,57 & 2 & 3 & 10 & 3,9 & 2,55 & 5 \\
\hline 0,13 & 7,51 & 3 & 1 & 3 & 4,56 & 1,32 & 5 \\
\hline 6,73 & 2,58 & 1 & 3 & 9 & 5,24 & 1,99 & 5 \\
\hline 4,42 & 3,78 & 2 & 2 & 6 & 3,91 & 1,67 & 5 \\
\hline 9,37 & 8,3 & 3 & 4 & 15 & 5,46 & 2,14 & 5 \\
\hline 8,49 & 0,16 & 1 & 3 & 9 & 5,45 & 0,65 & 5 \\
\hline 8,34 & 8,78 & 3 & 3 & 11 & 4,87 & 0,97 & 5 \\
\hline 2,51 & 6,8 & 3 & 1 & 3 & 5,42 & 3,92 & 6 \\
\hline 3,9 & 2,55 & 1 & 2 & 5 & 3,19 & 4,68 & 6 \\
\hline 3,7 & 7,84 & 3 & 2 & 7 & 4,7 & 5,28 & 6 \\
\hline 6,16 & 8,72 & 3 & 3 & 11 & 3,77 & 3,91 & 6 \\
\hline 8,36 & 7,46 & 3 & 3 & 11 & 5,02 & 5,88 & 6 \\
\hline 9,17 & 9,75 & 4 & 4 & 16 & 4,98 & 4,04 & 6 \\
\hline 2,13 & 4,59 & 2 & 1 & 2 & 4,42 & 3,78 & 6 \\
\hline 9,42 & 1,96 & 1 & 4 & 13 & 5,02 & 4,99 & 6 \\
\hline 2,28 & 7,01 & 3 & 1 & 3 & 3,21 & 5,92 & 6 \\
\hline 2,07 & 0,86 & 1 & 1 & 1 & 4,94 & 8,36 & 7 \\
\hline 0,71 & 5,69 & 2 & 1 & 2 & 4,29 & 7,78 & 7 \\
\hline
\end{tabular}

\begin{tabular}{|c|c|c|c|c|c|c|c|}
\hline \multicolumn{5}{|c|}{ DADOS NĀO CLASSIFICADOS } & \multicolumn{3}{|c|}{ DADOS CLASSIFICADO } \\
\hline $\begin{array}{c}\text { Coord. } \\
\text { X }\end{array}$ & $\begin{array}{c}\text { Coord. } \\
\text { Y }\end{array}$ & $\begin{array}{l}\text { Ind. } \\
\text { I }\end{array}$ & $\begin{array}{l}\text { Ind. } \\
\mathrm{J}\end{array}$ & $\begin{array}{c}\text { Num. } \\
\text { cel. }\end{array}$ & $\begin{array}{c}\text { Coord. } \\
\mathrm{X}\end{array}$ & $\begin{array}{c}\text { Coord. } \\
\text { Y }\end{array}$ & $\begin{array}{c}\text { Num. } \\
\text { cel. }\end{array}$ \\
\hline 1,71 & 6,28 & 3 & 1 & 3 & 3,7 & 7,84 & 7 \\
\hline 8,63 & 6,72 & 3 & 3 & 11 & 3,5 & 6,4 & 7 \\
\hline 5,46 & 2,14 & 1 & 2 & 5 & 4,49 & 6,83 & 7 \\
\hline 0,8 & 6,04 & 3 & 1 & 3 & 5,38 & 8,09 & 7 \\
\hline 9,78 & 4,18 & 2 & 4 & 14 & 5,97 & 7,94 & 7 \\
\hline 5,24 & 1,99 & 1 & 2 & 5 & 3,26 & 8,94 & 7 \\
\hline 4,49 & 6,83 & 3 & 2 & 7 & 5,38 & 6,62 & 7 \\
\hline 5,02 & 5,88 & 2 & 2 & 6 & 4,39 & 9,72 & 8 \\
\hline 6,77 & 0,8 & 1 & 3 & 9 & 3,02 & 9,38 & 8 \\
\hline 2,68 & 2,95 & 1 & 1 & 1 & 5,07 & 9,05 & 8 \\
\hline 7,29 & 4,23 & 2 & 3 & 10 & 6,78 & 1,46 & 9 \\
\hline 5,07 & 9,05 & 4 & 2 & 8 & 7,01 & 1,12 & 9 \\
\hline 6,35 & 7,57 & 3 & 3 & 11 & 8,49 & 0,16 & 9 \\
\hline 9,9 & 6,93 & 3 & 4 & 15 & 7,95 & 2,17 & 9 \\
\hline 5,38 & 8,09 & 3 & 2 & 7 & 7,83 & 0,4 & 9 \\
\hline 8,81 & 1,49 & 1 & 3 & 9 & 6,77 & 0,8 & 9 \\
\hline 9,89 & 0,59 & 1 & 4 & 13 & 8,81 & 1,49 & 9 \\
\hline 1,2 & 7,52 & 3 & 1 & 3 & 8,18 & 2,73 & 9 \\
\hline 8,18 & 2,73 & 1 & 3 & 9 & 6,73 & 2,58 & 9 \\
\hline 7,95 & 2,17 & 1 & 3 & 9 & 7,02 & 3,02 & 10 \\
\hline 5,42 & 3,92 & 2 & 2 & 6 & 6,07 & 3,86 & 10 \\
\hline 7,01 & 1,12 & 1 & 3 & 9 & 8,93 & 3,62 & 10 \\
\hline 0,16 & 0,03 & 1 & 1 & 1 & 7,29 & 4,23 & 10 \\
\hline 5,02 & 4,99 & 2 & 2 & 6 & 8,33 & 4,07 & 10 \\
\hline 9,02 & 2,36 & 1 & 4 & 13 & 8,11 & 5,57 & 10 \\
\hline 2,01 & 8,23 & 3 & 1 & 3 & 7,48 & 5,81 & 10 \\
\hline 0,55 & 1,84 & 1 & 1 & 1 & 6,62 & 5,64 & 10 \\
\hline 7,84 & 7,3 & 3 & 3 & 11 & 6,56 & 4,38 & 10 \\
\hline 7,48 & 5,81 & 2 & 3 & 10 & 8,36 & 7,46 & 11 \\
\hline 9,6 & 5,12 & 2 & 4 & 14 & 7,25 & 6,4 & 11 \\
\hline 2,14 & 1,75 & 1 & 1 & 1 & 6,25 & 6 & 11 \\
\hline 5,97 & 7,94 & 3 & 2 & 7 & 8,63 & 6,72 & 11 \\
\hline 4,87 & 0,97 & 1 & 2 & 5 & 7,84 & 7,3 & 11 \\
\hline 7,25 & 6,4 & 3 & 3 & 11 & 6,35 & 7,57 & 11 \\
\hline 9,62 & 3,48 & 2 & 4 & 14 & 8,34 & 8,78 & 11 \\
\hline 5,45 & 0,65 & 1 & 2 & 5 & 7,21 & 8,99 & 11 \\
\hline 1,85 & 1,83 & 1 & 1 & 1 & 6,16 & 8,72 & 11 \\
\hline 3,26 & 8,94 & 3 & 2 & 7 & 7,45 & 9,74 & 12 \\
\hline 1,83 & 2,9 & 1 & 1 & 1 & 6,29 & 9,16 & 12 \\
\hline 6,07 & 3,86 & 2 & 3 & 10 & 8,08 & 9,36 & 12 \\
\hline 0,48 & 9,27 & 4 & 1 & 4 & 9,02 & 2,36 & 13 \\
\hline 8,93 & 3,62 & 2 & 3 & 10 & 9,42 & 1,96 & 13 \\
\hline 4,56 & 1,32 & 1 & 2 & 5 & 9,89 & 0,59 & 13 \\
\hline 4,94 & 8,36 & 3 & 2 & 7 & 9,62 & 3,48 & 14 \\
\hline 9,4 & 7,38 & 3 & 4 & 15 & 9,6 & 5,12 & 14 \\
\hline 0,86 & 8,59 & 3 & 1 & 3 & 9,78 & 4,18 & 14 \\
\hline 4,7 & 5,28 & 2 & 2 & 6 & 9,4 & 7,38 & 15 \\
\hline 1,45 & 3,13 & 2 & 1 & 2 & 9,9 & 6,93 & 15 \\
\hline 3,19 & 4,68 & 2 & 2 & 6 & 9,37 & 8,3 & 15 \\
\hline 2,08 & 3,22 & 2 & 1 & 2 & 9,17 & 9,75 & 16 \\
\hline
\end{tabular}


(1983), que incluiu o armazenamento temporário das intersecçöes para a recuperação das mesmas curva por curva para o traçado contínuo. Esta modificação permitiu àquele autor fazer anotações do valor da curva sobre a mesma durante o traçado. O método das células, originalmente desenvolvido, não permitia fazer anotações sobre a curva e apresentava um tempo de desenho muito grande, pois a cada par de pontos havia necessidade de deslocamento da pena do plotter para a posição do outro par de pontos.

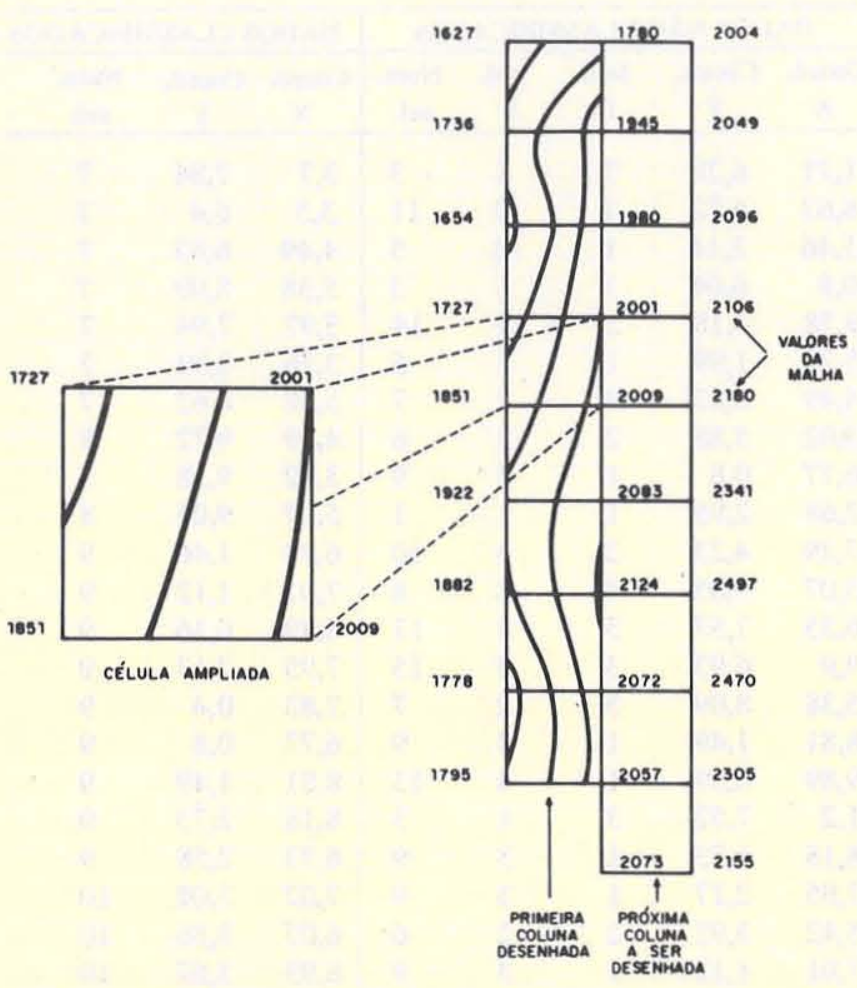

Figura 20 - Pesquisa e traçado das curvas de contorno pelo método das células, segundo IBM (1965)

- O segundo, denominado método de rastreamento (Fig. 21), é o mais comum entre os algoritmos utilizados nos programas de computação para traçado automático de curvas de contorno, inclusive naqueles disponíveis comercialmente. Este algoritmo segue as curvas de contorno, ou seja, a partir de algum ponto inicial são pesquisados os demais pontos que pertencem a uma determinada curva até coincidir ou com o ponto inicial (curva fechada), ou com a borda mapa (curva aberta). Os principais algoritmos desse tipo foram descritos por Dayhoff (1963), Batcha \& Reese (1964), Cottafava \& Le Moli (1969), Palmer (1970) e Snyder (1978).

Foi adotado neste trabalho o método de rastreamento para pesquisa e desenho das curvas de isovalores, porque este pode ser facilmente implementado em programas de computação.

Especificamente, foi adotado o método de contorno descrito por Batcha \& Reese (1964), no qual o interior de uma célula é subdividido em quatro triângulos, cujo vértice comum É o ponto central da célula e calculado como sendo a média aritmética dos quatro nós da célula. A figura 22 mostra os traçados possíveis de um trecho da curva de contorno quando a célula não é subdividida e também quando a mesma é subdividida em dois e quatro triângulos. A subdivisão do interior da célula em quatro triângulos introduz uma melhora no aspecto final da curva, pois a mesma fica mais suavizada.

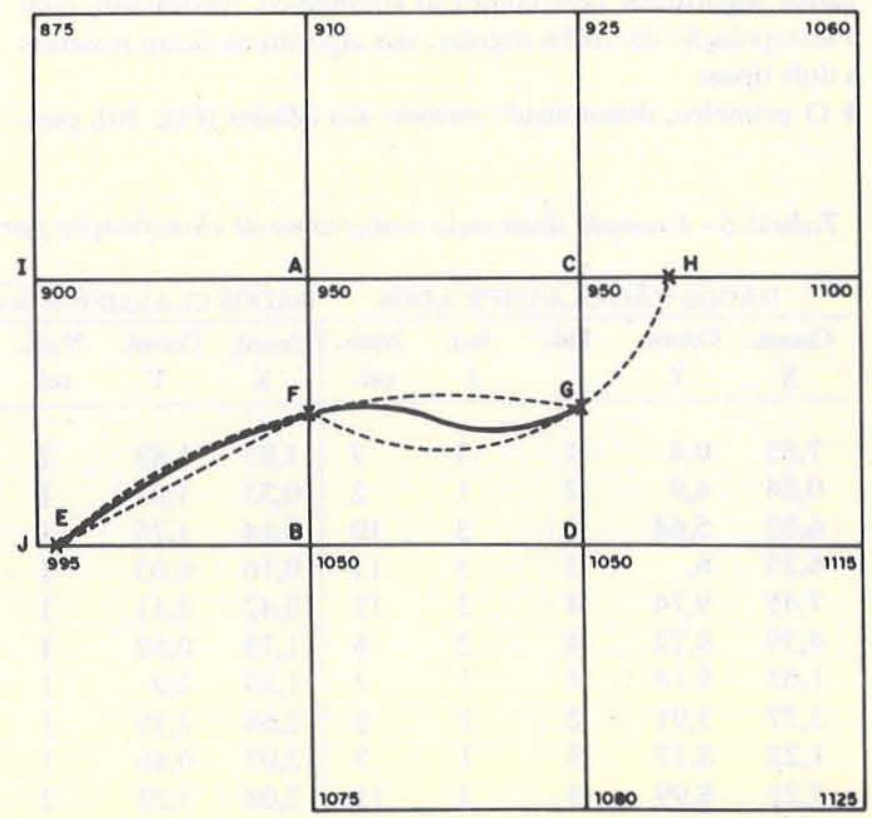

Figura 21 - Pesquisa e traçado da curva de contorno pelo método do rastreamento, segundo IBM (1965)

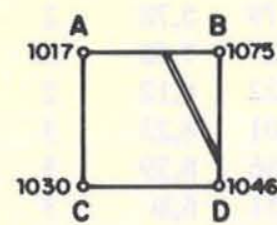

(a)

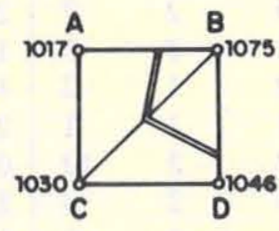

(b)

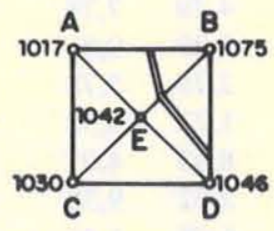

(c)
Figura 22 - Traçados posslveis de um trecho da curva no interior de uma célula, quando esta não é subdividida em triângulos (a), subdividida em dois triângulos (b) e subdividida em quatro triângulos (c), segundo Batcha \& Reese 1964

Quando o mapa de contorno for muito grande, e conseqüentemente o número de células, é conveniente subdividir o mesmo em partes e processá-las individualmente. Este procedimento pode diminuir o tempo de processamento à medida que muitas células que não apresentam uma determinada curva deixam de ser pesquisadas.

Projeção em perspectiva Uma outra representação gráfica possível de um arranjo regular de dados é a projeção em perspectiva, que tem um caráter apenas qualitativo. Essas representaçöes permitem que as superficies, topográficas ou não, sejam facilmente visualizadas e interpretadas.

A projeção em perspectiva consiste em tomar as três coordenadas da malha regular transformando-as em duas que são lançadas no plano. A união de todos esses pontos no plano irá produzir o desenho em perspectiva da superfície ou do modelo digital. 
A figura 23 mostra geometricamente como é obtida a perspectiva de um determinado objeto ou ślido. Nela pode-se ver que a perspectiva é função da posição e da distância do observador em relação ao objeto.

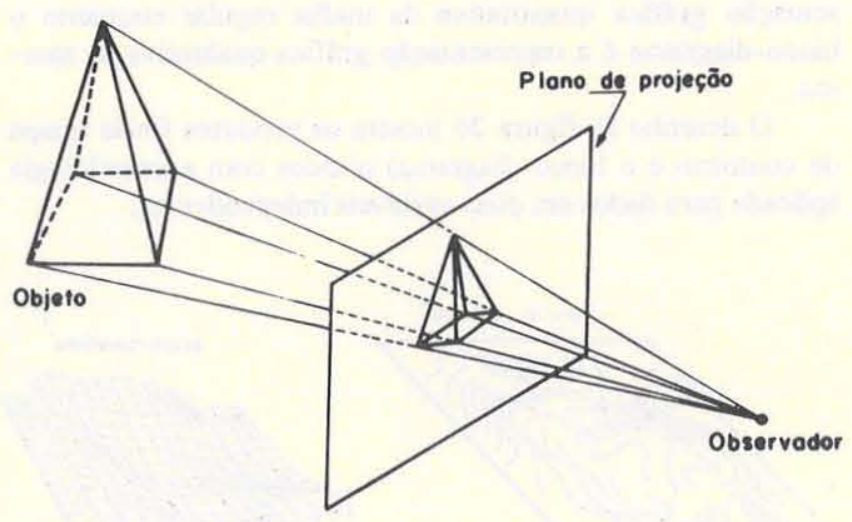

Figura 23 - Desenho mostrando a geometria da projeção em perspectiva (baseado em Bouknight 1983)

As transformações necessárias para se fazer a projeção em perspectiva foram desenvolvidas por Kubert et al. (1968). É preciso ressaltar que todas as referências consultadas sobre o desenho automático em perspectiva de objetos ou superffcies utilizam o algoritmo desenvolvido por aqueles autores. Tais cálculos encontram-se descritos a seguir.

Dado o ponto de coordenadas (cx,cy,cz) onde se localiza o observador e o ponto (ccx,ccy,ccz), centro do plano de projeção, calcula-se a distância (D):

$$
D=\left[(c x-c c x)^{2}+(c y-c c y)^{2}+(c z-c c z)^{2}\right]^{1 / 2}
$$

A reta de distância D que une esses dois pontos ê denominada linha de visada. Os ângulos dessa linha em relação aos eixos X, Y e Z são calculados pelas fórmulas (53), (54) e (55), respectivamente:

$$
\begin{aligned}
& \alpha=\operatorname{acos}[c c x-c x) / D] \\
& \beta=\operatorname{acos}[(c c y-c y) / D] \\
& \gamma=\operatorname{acos}[c c z-c z) / D]
\end{aligned}
$$

Com esses elementos, pode-se calcular a transformação em perspectiva de um ponto qualquer de coordenadas $(X, Y, Z)$ para um ponto no plano de projeção definido como (xp, yp).

A seqüência de cálculos é a que segue:

$$
\begin{aligned}
& \mathrm{QX}=\mathrm{cX}+\mathrm{D} \cdot \cos (\alpha) \\
& \mathrm{QY}=\mathrm{cy}+\mathrm{D} \cdot \cos (\beta) \\
& \mathrm{QZ}=\mathrm{cz}+\mathrm{D} \cdot \cos (\gamma)
\end{aligned}
$$

$\mathrm{AK}=\mathrm{D} /[(\mathrm{X}-\mathrm{cx}) \cdot \cos (\alpha)+(\mathrm{Y}-\mathrm{cy}), \cos (\beta)+$

$(\mathrm{Z}-\mathrm{cz}) \cdot \cos (\gamma)]$

$$
\begin{aligned}
& R X=c x+A K \cdot(X-c x) \\
& R Y=c y+A K \cdot(Y-c y) \\
& R Z=c z+A K \cdot(Z-c z)
\end{aligned}
$$

Finalmente, calcula-se (xp,yp) como:

$$
\begin{aligned}
& x p=[(R X-Q X) \cdot \cos (\beta)- \\
& (R Y-Q Y) \cdot \cos (\alpha)] / \operatorname{sen}(\gamma) \\
& y p=(R Z-Q Z) / \operatorname{sen}(\gamma)
\end{aligned}
$$

Dessa forma, calculam-se as transformações de todos os pontos da malha regular obtendo-se, assim, o conjunto de pontos que compõem a projeção em perspectiva de uma superfície qualquer.

Eliminação de linhas ocultas $\mathrm{O}$ passo seguinte à transformação em perspectiva da malha regular seria a obtenção do desenho pela união de todos os pares de pontos. Entretanto, a simples união desses pontos irá produzir um desenho em que várias linhas estarão cruzando-se. Isso acontece porque certas linhas ou trechos das mesmas, em função da perspectiva, ficarão ocultas ao observador. Essas linhas devem ser eliminadas antes do desenho das mesmas pela aplicação e algoritmos especfficos para esse fim. A figura 24 mostra um bloco-diagrama com as linhas ocultas desenhadas enquanto na figura 25 tem-se o mesmo desenho em que essas linhas foram eliminadas.

Os principais algoritmos para a eliminação de linhas ocultas para desenho em perspectiva de superficies representadas por malhas regulares foram apresentados por Kubert et al. (1968), Williamson (1972), Graham (1972), Wright (1973) e Anderson (1982).

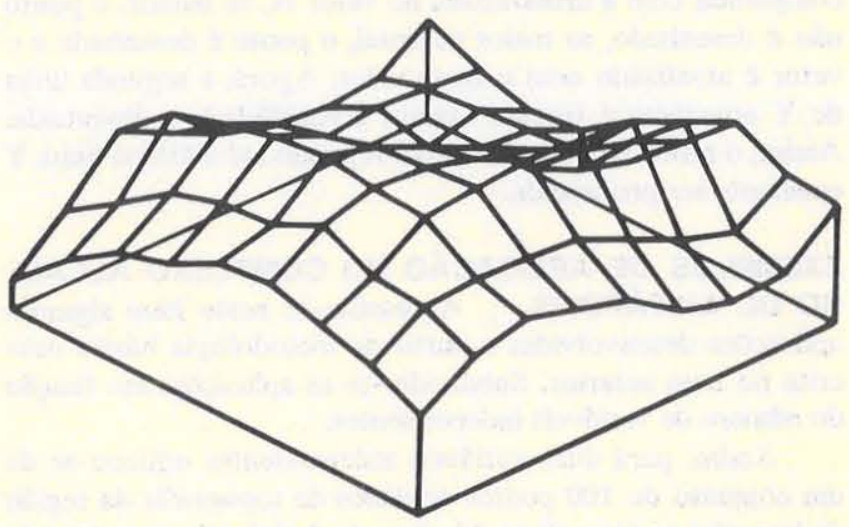

Figura 24 - Bloco-diagrama de uma superficie com as linhas ocultas desenhadas (Pettinati 1983) 


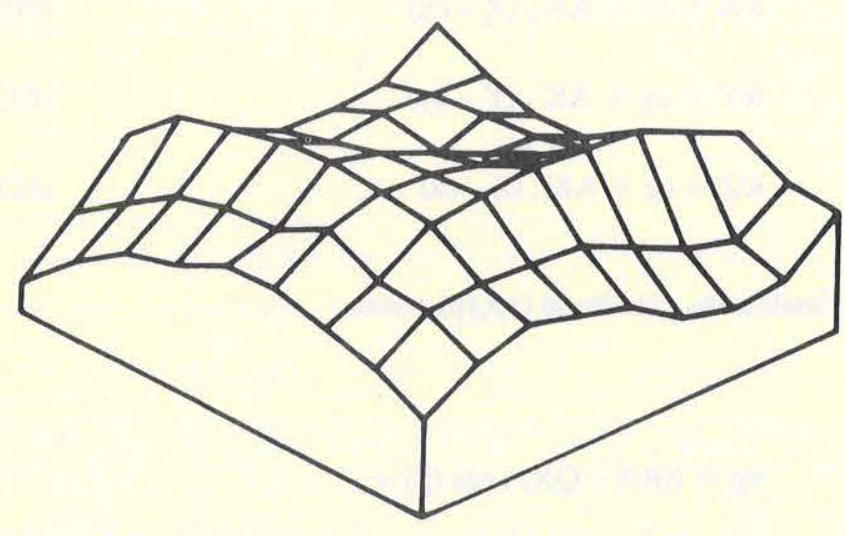

Figura 25 - Bloco-diagrama da mesma superflcie com as linhas ocultas eliminadas (Pettinati 1983)

Entre esses algoritmos, foi escolhido o publicado por Wright (1973), que, por ser bastante simples, é facilmente implementado em programas de computação para desenho em perspectiva de superfície.

O algoritmo de Wright trabalha no plano de projeção, que pode ser ora a tela do monitor de vídeo, ora o plano da mesa do plotter. Nesse plano de projeção define-se um vetor $\mathrm{H}$, paralelo ao eixo $\mathrm{XP}$, cuja dimensão será igual à resolução da unidade de saída que for utilizada. Por exemplo, se o dispositivo de saída for um monitor de vídeo com resolução de 1.024 por 1.024 pontos, o vetor $\mathrm{H}$ seria dimensionado com 1.024 posições.

$\mathrm{O}$ vetor $\mathrm{H}$ é utilizado para armazenar as alturas, abaixo

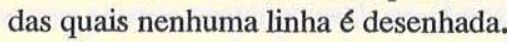

O processamento começa pela escolha do eixo de coordenadas no sistema original, que está mais próximo ao observador. Se, por exemplo, este for o eixo $\mathrm{Y}$, então as linhas de $\mathrm{Y}$ constante ou paralelas ao eixo $\mathrm{X}$ serão desenhadas.

A primeira linha, por estar mais próxima do observador, será totalmente visível e, portanto, totalmente desenhada. $\mathrm{O}$ vetor $\mathrm{H}$ é armazenado com os valores de altura dessa linha. Isso significa que nenhuma linha ou trecho dela com altura menor que a encontrada na primeira será desenhada. Antes de prosseguir com o processamento da segunda linha de Y constante, processam-se todos os trechos das linhas de X constante compreendidos entre a primeira e a segunda linhas. Para cada trecho das linhas de $\mathrm{X}$ constante, a altura do ponto é comparada com a armazenada no vetor $\mathrm{H}$, se menor, o ponto não é desenhado, se maior ou igual, o ponto é desenhado e o vetor $\hat{e}$ atualizado com o novo valor. Agora, a segunda linha de $\mathrm{Y}$ constante é testada quanto à visibilidade e desenhada. Assim, o procedimento descrito é repetido até a última linha $\mathrm{Y}$ constante ser processada.

EXEMPLOS DE APLICAÇÃO NO COMPLEXO ALCALINO DE ANITÁPOLIS Apresenta-se neste item algumas aplicações desenvolvidas a partir da metodologia básica descrita no item anterior. Subdividiu-se as aplicações em função do número de variáveis independentes.

Assim, para duas variáveis independentes utilizou-se de um conjunto de 100 pontos de dados de topografia da região da intrusão do Complexo Alcalino de Anitápolis, extraídos da Folha SG-22-Z-D-IV (IBGE 1976). E, finalmente, para exemplificar as aplicações com dados em três variáveis independentes utilizou-se dos dados de análises químicas distribuí- dos ao longo de 40 furos de sondagem totalizando 396 pontos de dados.

Representações gráficas de malhas regulares bidimensionais As representações gráficas espaciais mais usuais para dados em duas variáveis independentes são o mapa de contorno e o bloco-diagrama. O mapa de contorno é a representação gráfica quantitativa da malha regular enquanto o bloco-diagrama é a representação gráfica qualitativa da mesma.

O desenho da figura 26 mostra os produtos finais (mapa de contorno e o bloco-diagrama) obtidos com a metodologia aplicada para dados em duas variáveis independentes.
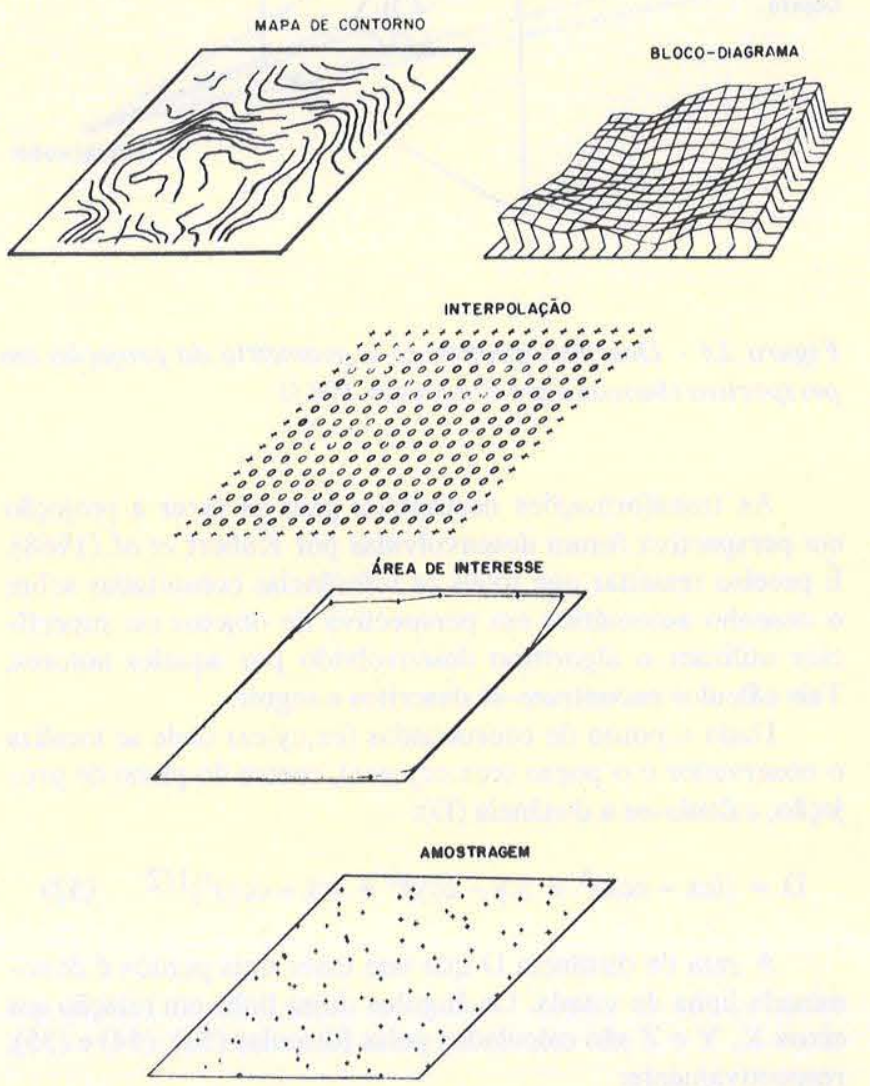

Figura 26 - Representações gráficas espaciais de dados em duas variaveis independentes

A figura 27 apresenta o mapa de localização dos pontos bem como a fronteira convexa dos mesmos. A interpolação da malha regular foi feita somente dentro do domínio da fronteira convexa.

A figura 28 apresenta o mapa de contorno que representa, aproximadamente (em função dos 100 pontos de amostragem), a superfície topográfica na região da intrusão do Complexo.

A interpolação da malha regular de $17 \times 17$ nós foi feita pelo ajuste local de equações multiquádricas, utilizando-se dos 16 pontos vizinhos próximos e constante $C$ igual a 16 vezes a distância média entre os pontos de dados. Utilizou-se de constantes grandes porque os ajustes, das equações multiquádricas, foram feitos no domínio logarítmico com o objetivo de diminuir a variabilidade dos dados e, conseqüentemente, obter ajustes mais precisos. 


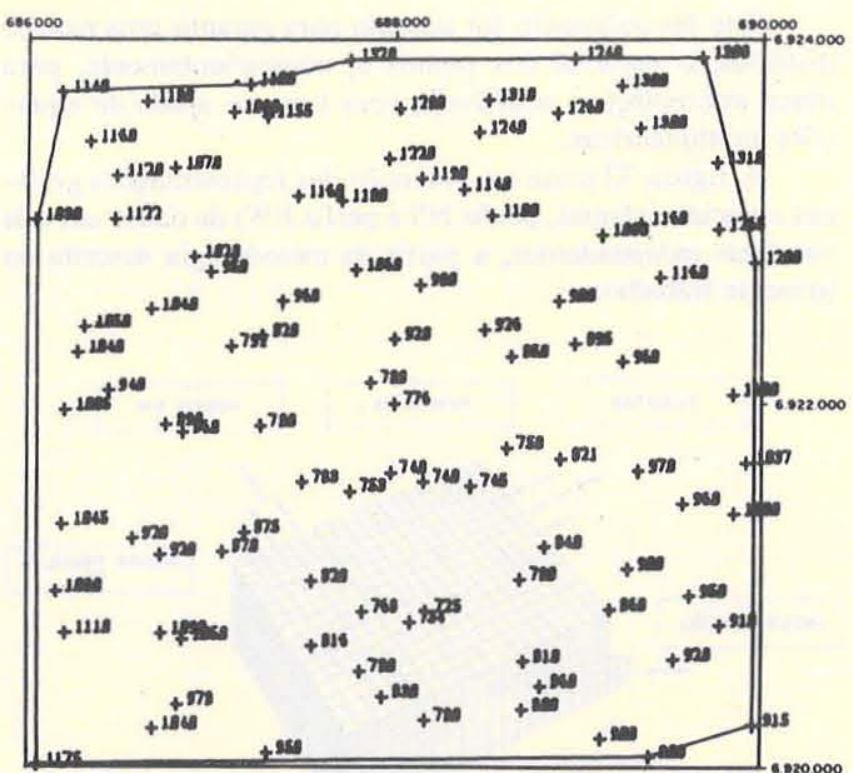

Figura 27 - Mapa de localização dos pontos de dados de topografia com desenho da fronteira convexa dos mesmos

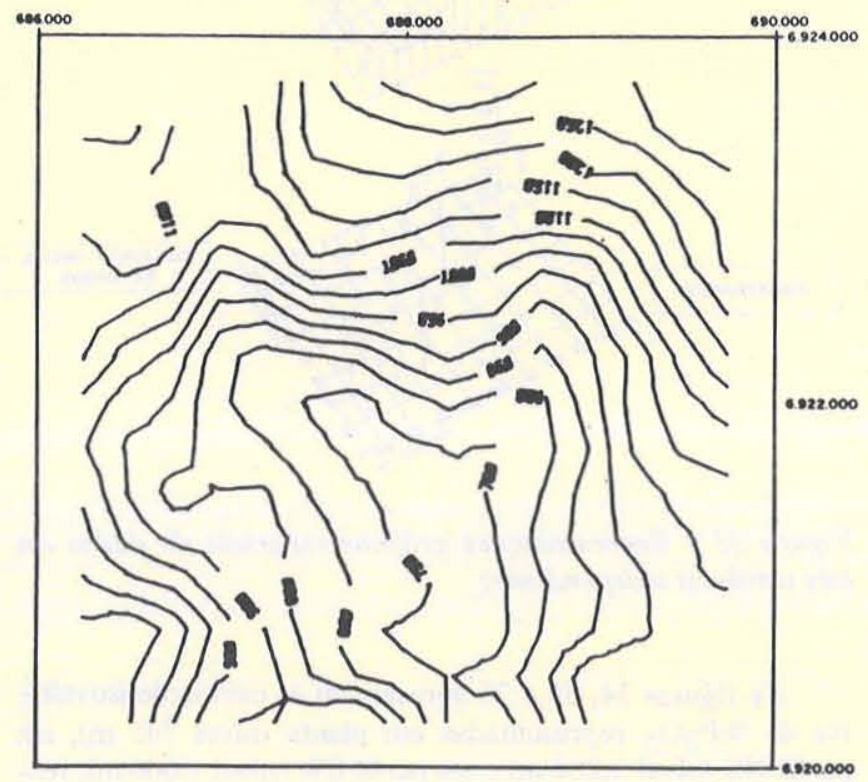

Figura 28 - Mapa de contorno dos dados de topografia da região do Complexo Alcalino de Anitápolis

O contorno automático foi efetuado pelo método do rastreamento.

A projeção em perspectiva da malha regular interpolada resulta no bloco-diagrama, que é a forma de representação gráfica qualitativa da mesma. Os parâmetros da perspectiva, que determinam a posição do observador em relação à superfície, das três visadas escolhidas (Fig. 29) encontram-se listados na tabela 7.

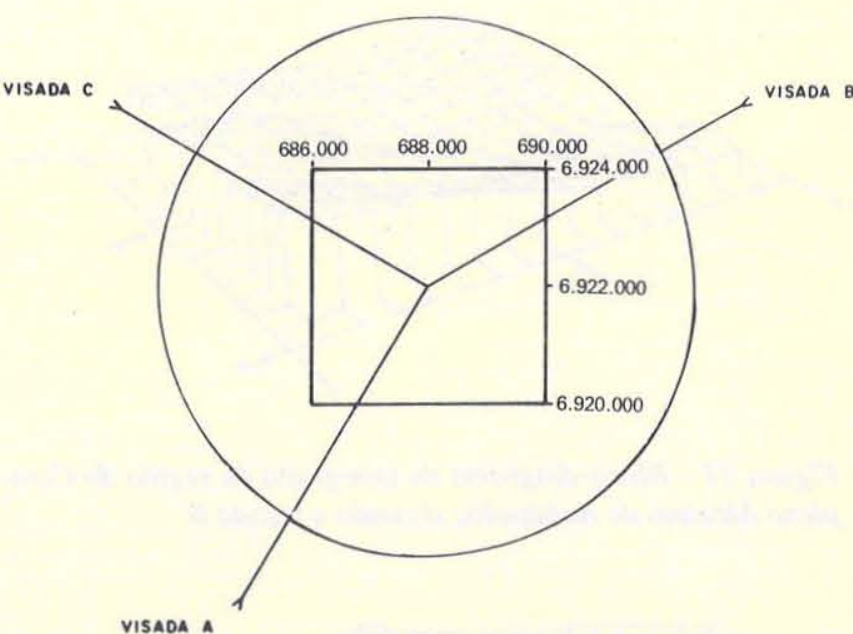

Figura 29 - Desenho esquemático mostrando a localização das visadas $A, B$ e $C$

Tabela 7 - Parâmetros das perspectivas A, B e C

\begin{tabular}{c|r|r|c|c}
\hline Visada & \multicolumn{1}{|c|}{$\alpha$} & \multicolumn{1}{c|}{$\beta$} & \multicolumn{1}{c|}{$\gamma$} & Distância (m) \\
\hline A & 61,65 & 37,79 & 112,78 & $10,846,19$ \\
B & 142,98 & 117,45 & 112,78 & $10.846,19$ \\
C & 37,02 & 117,45 & 112,78 & $10.845,19$ \\
\hline
\end{tabular}

As figuras $30,31 \mathrm{e} \cdot 32$ apresentam os blocos-diagramas das visadas A, B e C, respectivamente. Nessas figuras podemse observar a zona central deprimida bem como as principais drenagens.

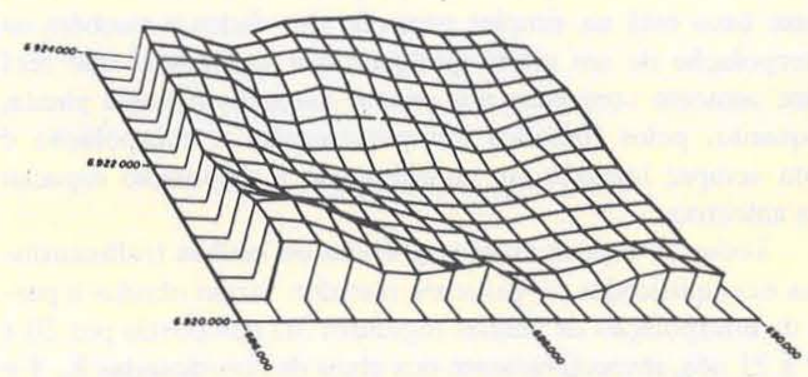

Figura 30 - Bloco-diagrama da topografia da região do Complexo Alcalino de Anitápolis, segundo a visada A

Representações gráficas de malhas regulares tridimensionais As vantagens de se conhecer o mapa tridimensional de uma jazida ou a geometria do corpo mineralizado são claras. Por exemplo, numa fase inicial da pesquisa de úm jazimento qualquer, o conhecimento do mapa da variação espacial do minério poderá orientar os trabalhos futuros de pesquisa e, já na fase de exploração, poderá orientar os trabalhos de lavra, incluindo desmonte e mistura de blocos de diferentes teores. 


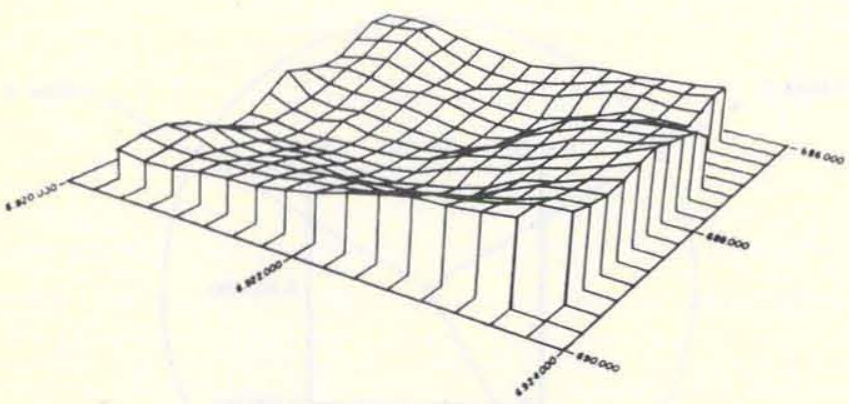

Figura 31 - Bloco-diagrama da topografia da região do Complexo Alcalino de Anitápolis, segundo a visada $B$

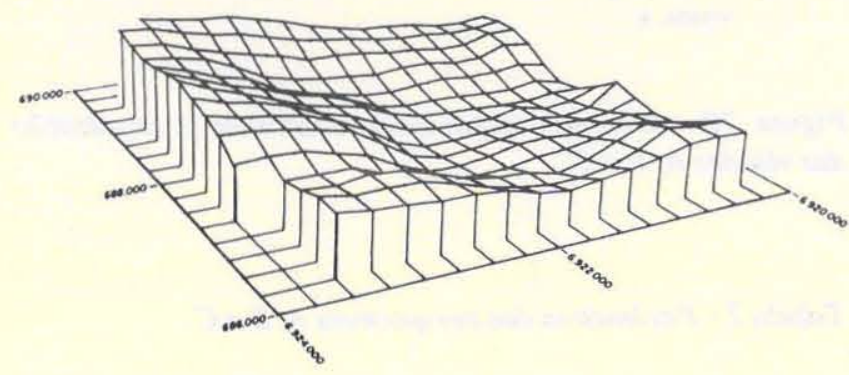

Figura 32 - Bloco-diagrama da topografia da região do Complexo Alcalino de Anitápolis, segundo a visada $C$

A obtenção das representações gráficas de malhas tridimensionais como perfis e plantas so é possível fazendo a interpolação de uma malha regular em 3D. A obtenção de plantas e perfis de modo manual $\varepsilon$ aproximada porque não leva em consideração a ponderação espacial dos dados. Por exemplo, na obtenção manual de uma planta a um determinado nfvel da jazida, seriam considerados somente as amostras que porventura caíssem naquele nível e algumas que em função da proximidade seriam simplesmente projetadas no mesmo. $\mathrm{O}$ erro nesse caso está na simples projeção dos dados e também na interpolação de um ponto qualquer não amostrado, que será feita somente com base nos pontos lançados naquela planta, enquanto, pelos métodos computacionais, a interpolação é feita sempre levando em consideração a disposição espacial das amostras.

Todas as representaçōes gráficas de malhas tridimensionais exemplificadas no presente trabalho foram obtidas a partir da interpolação de malhas regulares 3D compostas por $20 \mathrm{x}$ 17 x 21 nós, respectivamente nos eixos de coordenadas X, Y e Z. Essas interpolações foram feitas utilizando-se equações multiquádricas locais, ajustadas com base nos 24 pontos vizinhos ao nó e constante C igual a 0,02 vez a distância média entre amostras.

Devido à distribuição semi-regular dos pontos de dados (ao longo dos furos de sondagem), a pesquisa dos vizinhos próximos foi feita após a subdivisão da região em torno do nó em oito setores e tomando-se os três pontos mais próximos em cada um desses, totalizando 24 pontos. Impondo-se essa restrição, muitos nós, principalmente os situados no limite da fronteira convexa, não seriam interpolados porque alguns setores estariam vazios e o critério de 24 pontos não seria satisfeito. Assim, para esses casos, adotou-se um limite mínimo de 8 pontos para que o nó pudesse ser interpolado.
Este procedimento foi adotado para garantir uma melhor distribuição espacial dos pontos e, conseqüentemente, para obter interpolações confiáveis, com base no ajuste de equações multiquádricas.

A figura 33 mostra a obtenção das representações gráficas espaciais (plantas, perfis NS e perfis EW) de dados em três variáveis independentes, a partir da metodologia descrita no presente trabalho.

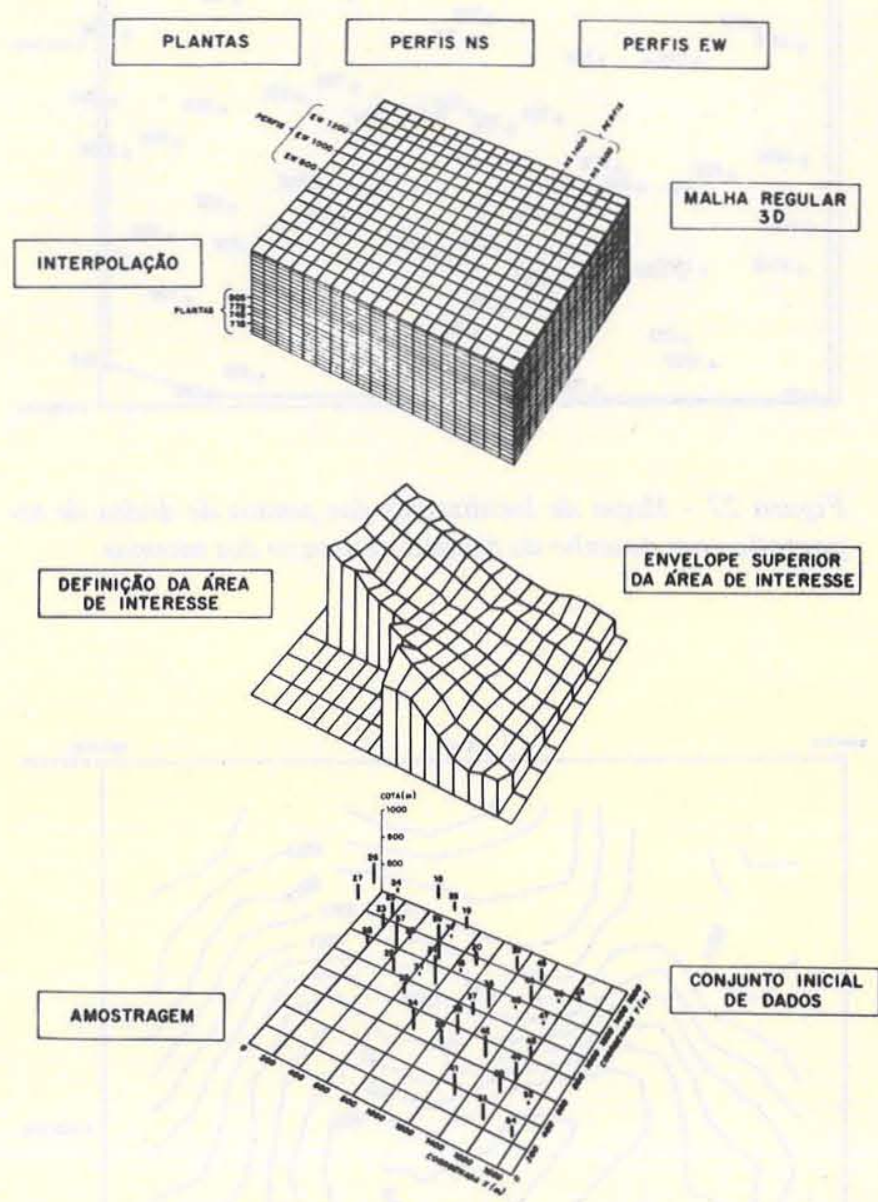

Figura 33 - Representações gráficas espaciais de dados em três variáveis independentes

As figuras 34,35 e 36 apresentam as curvas de isovalores de $\% \mathrm{P}_{2} \mathrm{O}_{5}$ representadas em planta (nível $745 \mathrm{~m}$ ), em perfil NS (nível $1.200 \mathrm{~m}$ ) e em perfil EW (nível $1.000 \mathrm{~m}$ ), respectivamente.

CONSIDERAÇÕES FINAIS A metodologia básica apresentada no presente trabalho permite automatizar o procedimento para obtenção de representações gráficas espaciais em geociências auxiliadas por computador, liberando o técnico especializado, que normalmente faz o traçado manual dessas figuras, para tarefas mais nobres. Nesse sentido, o domínio da metodologia é de vital importância para a produção automática de desenhos confiáveis e de alta qualidade.

Embora os programas de computação, segundo a metodologia apresentada, tenham sido escritos e instalados em computadores de grande porte, atualmente é possível adaptálos para microcomputadores nacionais de 16 bites (estações de trabalhos independentes), tornando o sistema totalmente portátil e compatível. 


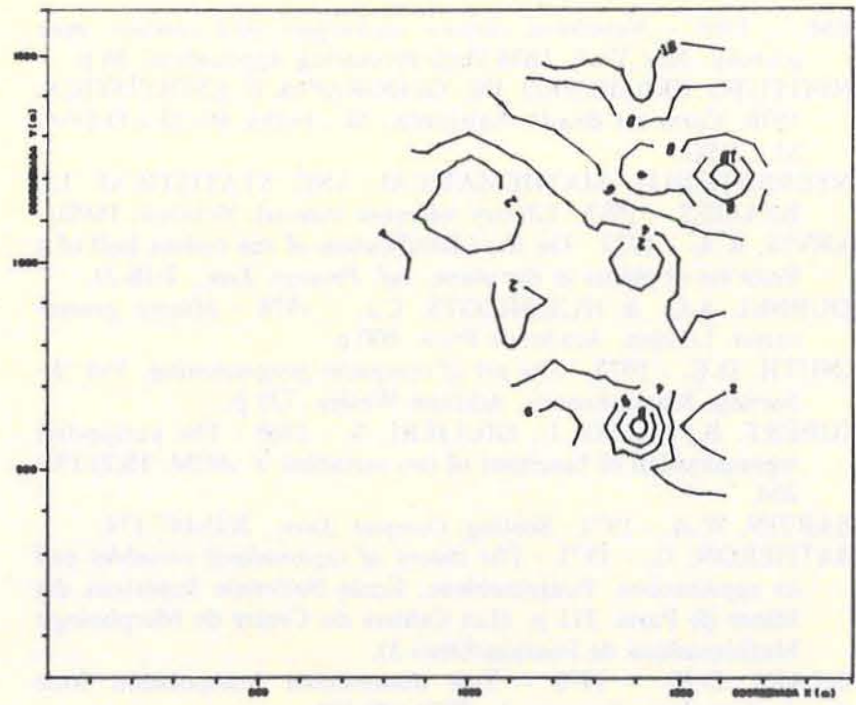

Figura 34 - Curvas de isovalores de $\% \mathrm{P}_{2} \mathrm{O}_{5}$ na planta do ntvel de $745 \mathrm{~m}$

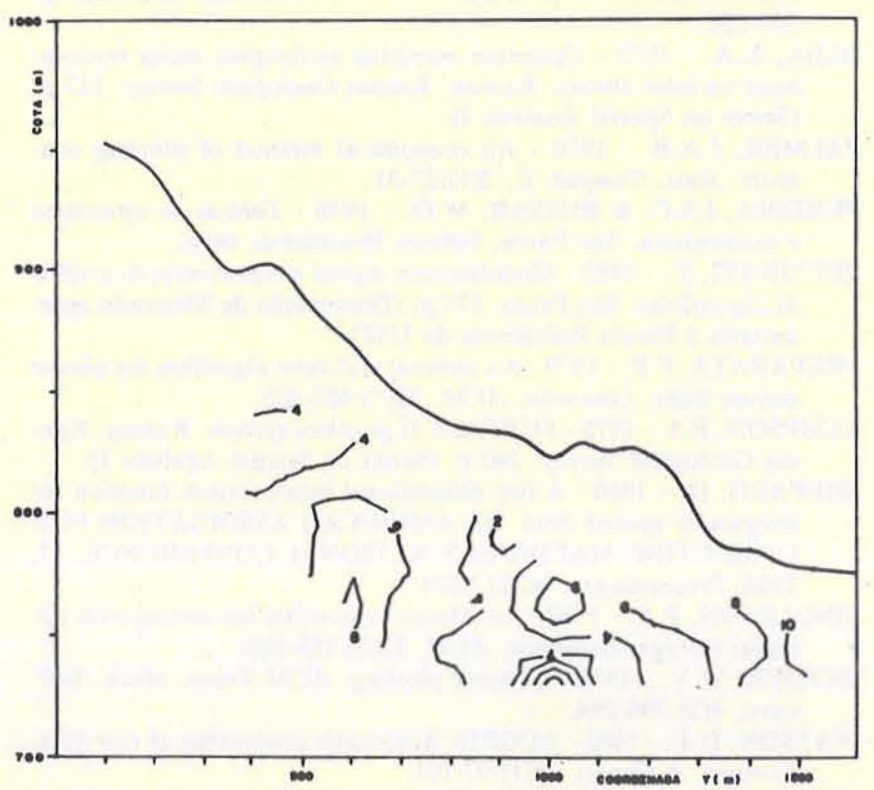

Figura 35 - Curvas de isovalores de $\% \mathrm{P}_{2} \mathrm{O}_{5}$ no perfil WS 1.200

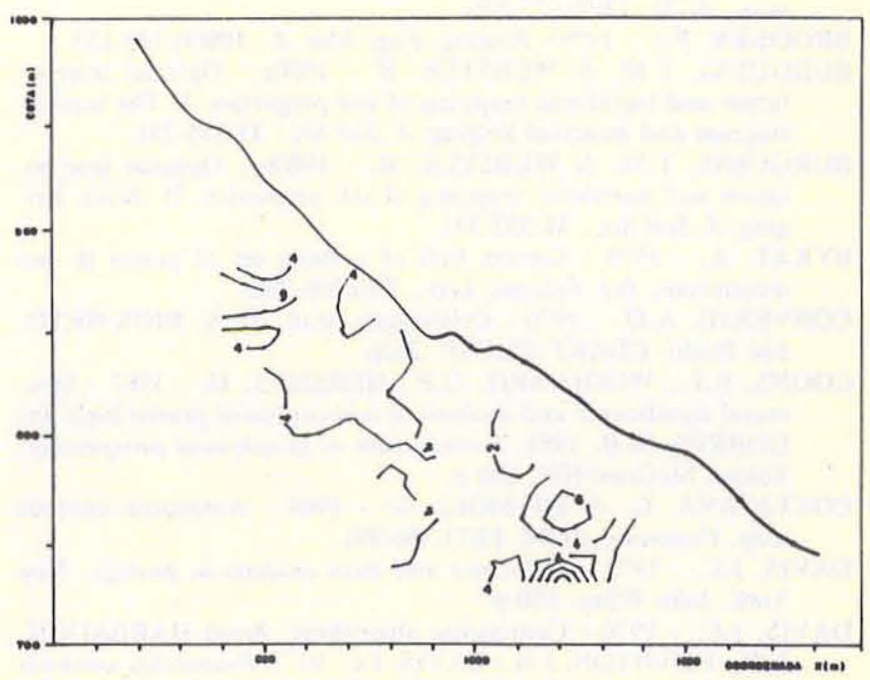

Figura 36 - Curvas de isovalores de $\% \mathrm{P}_{2} \mathrm{O}_{5}$ no perfil EW 1.000

Finalmente, o trabalho teve como objetivo descrever a metodologia básica, a partir da qual poderão ser obtidas outras formas de representações gráficas espaciais de dados geologicos. Por exemplo, a partir das técnicas de projeção em perspectiva e eliminação de linhas ocultas podem-se obter diagramas em cerca e blocos-diagramas compostos. Portanto, a metodologia apresentada é passível de modificaçỏes e adaptaçőes para atender à necessidade específica em algum tipo de representação gráfica do pesquisador.

Agradecimentos $\mathrm{O}$ autor expressa seus mais sinceros agradecimentos a todas as pessoas que direta ou indiretamente colaboraram para a realização deste trabalho. Ao Professor Dr. Gilberto Amaral, pela orientação e estímulo dados à dissertação de Mestrado do Autor, da qual foi derivado este artigo. Ao Professor Dr. Paulo Milton Barbosa Landim, pela criteriosa revisão do manuscrito e sugestões dadas. Ao Instituto de Pesquisas Tecnológicas do Estado de São Paulo, que assegurou o apoio institucional durante o desenvolvimento do projeto de pesquisa. Às Indústrias Luchisinger Madörin S.A., pela autorização dada ao uso dos dados de análises químicas.

\section{REFERÊNCIAS BIBLIOGRÁFICAS}

AKIMA. H. - 1974 - A method of bivariate interpolation and smooth surface fitting based on local procedures. Commun. $A C M, 17(1): 26-31$.

AKIMA, H. - 1978 - A method of bivariate interpolation and smooth surface fitting for irregulary distributed data points. ACM Trans. Math. Software, 4(2):148-159.

AMARAL, G. - 1976 - Teste de análise de superfícies de tendência para distribuições aleatórias. In: CONGR. BRAS. GEOL., 29, Ouro Preto, 1976. Anais... Ouro Preto, SBG. V. 3, p. 233-237.
ANDERSON, D.P. - 1982 - Hidden line elimination in projected grided surfaces. ACM Trans. Graphics, 1(4):274-288.

ANDERSON, K.R. -1976 - Simple algorithm for positioning a point close to a boundary. Math. Geol., 8(1):105-106.

BARNHILL, R.E. - 1983 - A survey of the representation and design of surfaces. IEEE Comput. Graphics Appl., 3(7):9-16.

BATCHA, J.P. \& REESE, J.R. - 1964 - Surface determination and automatic contouring for mineral exploration, extraction, and processing. Q. Colo. Sch. Mines, 59(1):1-14. 
BENGTSSON, B. \& NORDBECK, S. - 1964 - Construction of isarithms and isarithmic maps by computer. BIT, 4:87-105.

BOUKNIGHT, W.J. - 1970 - A procedure for generation of threedimensional halftoned computer graphics presentations. Commun. ACM, 13(9):527-536.

BROOKER, P.I. - 1979 - Kriging. Eng. Min. J., 180(9):148-153.

BURGUESS, T.M. \& WEBSTER, R. - 1980a - Optimal interpolation and isarithmic mapping of soil properties, I: The semivariogram and punctual kriging. J. Soil Sci., 31:315-331.

BURGUESS, T.M. \& WEBSTER, R. - 1980b - Optimal interpolation and isarithmic mapping of soil properties, II: Block Kriging. J. Soil Sci., 31:333-341.

BYKAT, A. - 1978 - Convex hull of a finite set of points in two dimensions. Inf. Process. Lett., 7(6):296-298.

CONVERSE, A.O. - 1970 - Otimização. trad. de A. RIOS NETO, São Paulo. EDART/EDUSP. 262p.

COONS, R.L.; WOOLLARD, G.P.; HERSHEY, G. - 1967 - Structural significance and analysis of mid-continent gravity high. In: DOBRIN, M.B. 1981. Introduction to geophysical prospecting . Tokyo, McGraw-Hill. 630 p.

COTTAFAVA, G. \& LE MOLI, G. - 1969 - Automatic contour map. Commun. ACM, 12(7):386-391.

DAVIS, J.C. - 1973 - Statistics and data analysis in geology. New York, John Wiley. $550 \mathrm{p}$.

DAVIS, J.C. - 1976 - Contouring algorithms. Apud HARBAUGH, J.W.; DOVETON, J.H.; DAVIS, J.C. 1977. Probability methods in oil exploration. New York, John Wiley. $269 \mathrm{p}$.

DAYHOFF, M.O. - 1963 - A contour-map program for X-ray crystallography. Commun. ACM, 6(10):620-622.

DELFINER, P. \& DELHOMME, J.P. - 1975 - Optimun interpolation by kriging. In: DAVIS, J.C. \& McCULLAGH, M.J. (eds.) Display and analysis of spatial data. New York, John Wiley. 378 p.

DORN, W.S. \& McCRAKEN, D.D. - 1978 - Cálculo númerico com estudos de casos em FORTRAN IV. trad. de J.A.R. dos SANTOS e A.L.S. de ALMEIDA. Rio de Janeiro, CAMPUS/EDUSP. $568 \mathrm{p}$.

DOUGENICK, J.A. \& SHEEHAN, D.E. - 1975 - SYMAP user's reference manual. Massachusetts, Laboratory for Computer Graphics and Spatial Analysis.

EDDY, W.F. - 1977 - A new convex hull algorithm for planar sets. ACM Trans. Math. Software, 3(4):348-403.

FADDEVA, V.N. - 1959 - Computational methods of linear algebra. New York, Dover Publications. 252 p.

FRANKE, R. - 1982 - Scattered data interpolation: Test of some methods. Math. Comput., 38(157):181-200.

FRANKE, R. \& NIELSON, G. - 1980 - Smooth interpolation of large sets of scattered data. Int. J. Num. Meth. Eng., 15:1691-1704.

GIANNINI, P.C.F. \& FERNANDES, H.G. - 1984 - Aplicação de análise de tendências por regressão múltipla a parâmetros sedimentológicos em duas áreas da costa sudoeste paulista. In: CONGR. BRAS. GEOL., 32, Rio de Janeiro, 1984. Anais... Rio de Janeiro, SBG. V. 1, p. 145-158.

GOLD, C.M.; CHARTERS, T.D.; RAMSDEN, J. - 1977 - Automated contour mapping using triangular element data structures and an interpolant over each irregular domain. Comput. Graphics, 11:170-175.

GRAHAM, R.L. - 1972 - An efficient algorithm for determining the convex hull of a finite planar set. Inf. Process. Lett., 1:132-133.

GREEN, P.J. \& SILVERMAN, B.W. - 1979 - Constructing the convex hull of a set of points in the plane. Comput. J., 22(3):262-266.

HALL, J.K. - 1975 - PTLOC - A FORTRAN subroutine for determining the position of a point relative to a closed boundary. Math. Geol., 7(1):75-79.

HARBAUGH, J.W. \& MERRIAM, D.F. - 1968 - Computer applications in stratigraphic analysis. New York, John Wiley. $282 \mathrm{p}$.

HARBAUGH, J.W.; DOVETON, J.H.; DAVIS, J.C. 1977. Probability methods in oil exploration. New York, John Wiley. $269 \mathrm{p}$.

HARDY, R.L. - 1971 - Multiquadric equations of topography and other irregular surfaces. J. Geophys. Res., 76(8):1905-1915.

HARDY, R.L. - 1972 - Analytical topographic surfaces by spatial intersection. Photogram. Eng., 38(5):452-458.

HARDY, R.L. - 1977 - Least squares prediction. Photogram. Eng. Remote Sens., 43(4):475-492.

HARDY, R.L. - 1985 - Comunicação pessoal recebida pelo autor.

HOWARTH, R.J. - 1983 - Mapping. In: HOWART, R.J. Statistics and data analysis in geochemical prospecting. Amsterdam, Elsevier. 437 p.
IBM. - 1965 - Numerical surface techniques and contour map plotting. New York, IBM Data Processing Application. $36 \mathrm{p}$.

INSTITUTO BRASILEIRO DE GEOGRAFIA E ESTATÍSTICA. 1976. Carta do Brasil; Anitápolis, SC, Folha SG-22-2-D-IV-4. SL., DSG.

INTERNATIONAL MATHEMATICAL AND STATISTICAL LIBRARIES. - 1982 - Library reference manual. Houston, IMSL.

JARVIS, R.A. - 1973 - On the identification of the convex hull of a finite set of points in the plane. Inf. Process. Lett., 2:18-21.

JOURNEL A.G. \& HUIJBREGTS, C.J. - 1978 - Mining geostatistics. London, Academic Press. 600 p.

KNUTH. D.E. - 1973 - The art of computer programming. Vol. 3 Sorting. Massachusetts, Addison-Wesley. 723 p.

KUBERT, B.; SZABO, J.; GIULIERI, S. - 1968 - The perspective representation of functions of two variables. J. $A C M, 15(2)$ :193204.

MARTIN, W.A. - 1971 - Sorting. Comput. Surv., 3(4):147-174.

MATHERON, G. - 1971 - The theory of regionalized variables and its applications. Fontainebleau, École Nationale Supérieux des Mines de Paris. 211 p. (Les Cahiers du Centre de Morphologie Mathématique de Fontainebleau 5).

McLAIN, D.H. - 1976 - Two dimensional interpolation from random data. Comput. J., 19(2):178-181.

McCALLUM, D. \& AVIS, D. - 1979 - A linear algorithm for finding the convex hull of a simple polygon. Inf. Process. Lett., 9(5):201-206.

MOORE, I.G. - 1977 - Automatic contouring of geological data. In: INTERNATIONAL SYMPOSIUM ON THE APPLICATION OF COMPUTERS AND MATHEMATICS IN THE MINERAL INDUSTRIES, 15, Brisbane, - 1977 - Proceedings. Brisbane. p. 209-220.

OLEA, R.A. - 1975 - Optimum mapping techniques using regionalized variable theory. Kansas, Kansas Geological Survey, 137 p. (Series on Spatial Analysis 2)

PALMER, J.A.B. - 1970 - An economical method of plotting contours. Aust. Comput. J., 2(1):27-31.

PEREIRA, J.S.C. \& BUSSAB, W.O. - 1976 - Tábuas de estatística e matemática. São Paulo, Editora Brasiliense, $66 \mathrm{p}$.

PETTINATI, F. - 1983 - Modelamento digital e representação gráfica de superfícies. São Paulo. 177 p. (Dissertação de Mestrado apresentada à Escola Politécnica da USP)

PREPARATA, F.P. - 1979 - An optimal real-time algorithm for planar convex hulls. Commun. ACM, 22(7):402-405.

SAMPSON, R.J. - 1975 - SURFACE II graphics system. Kansas, Kansas Geological Survey. 240 p. (Series on Spatial Analysis 1)

SHEPARD, D. - 1968 - A two dimensional interpolation function for irregularly spaced data. In: AMERICAN ASSOCIATION FOR COMPUTING MACHINERY NATIONAL CONFERENCE, 23, 1968. Proceedings... p. 517-524.

SINGLETON, R.C. - 1969- An efficient algorithm for sorting with minimal storage. Commun. ACM, 12(3):185-186.

SNYDER, W.V. - 1978 - Contour plotting. ACM Trans. Math. Software, 4(3):290-294.

WATSON, D.F. - 1982 - ACORD: Automatic contouring of raw data. Comput. \& Geosci., 8(1):97-101.

WEBSTER, R. \& BURGUESS, T.M. - 1980 - Optimal interpolation and isarithmic mapping of soil properties, III: Changing drift and universal kriging. J. Soil Sci., 31:505-524.

WILLIAMSON, H. - 1972 - Algorithm 420-Hidden-line plotting program. Collected Algorithms from CACM. p. 1-7.

WRIGHT, T.J. - 1973 - A two space solution to the hidden line problem for plotting functions of two variables. IEEE Trans. Comput., C-22(1):28-33.

YAMAMOTO, J.K. - 1986 - Representações gráficas espaciais em Geologia - Aplicações no Complexo Alcalino de Anitápolis. São Paulo.167p. (Dissertação de Mestrado, Instituto de Geociências da USP).

YOELI, P. - 1975 - Compilation of data for computer-assisted relief cartography. In: DAVIS, J.C. \& MACCULLAGH, M.J. (eds.) Display and analysis of spatial data. New York, John Wiley. p. 352-367.
Manuscrito 508

Recebido em 21 de outubro de 1987 Revisão aceita em 21 de dezembro de 1987 